\title{
Pumped heat energy storage with liquid media: Thermodynamic assessment by a Brayton-like model
}

\author{
D. Salomone-González a , J. González-Ayala ${ }^{\text {b,* }}$, A. Medina ${ }^{\text {b,c }}$, J.M.M. Roco ${ }^{\text {b,c }}$, P.L. Curto-Risso ${ }^{\text {a }}$, \\ A. Calvo Hernández ${ }^{\text {b,c }}$ \\ a Facultad de Ingeniería, Universidad de la República, Montevideo, Uruguay \\ ${ }^{\mathrm{b}}$ Instituto Universitario de Física Fundamental y Matemáticas (IUFFyM), Universidad de Salamanca, 37008 Salamanca, Spain \\ c Departamento de Física Aplicada, Universidad de Salamanca, 37008 Salamanca, Spain
}

\section{A R T I C L E I N F O}

\section{Keywords:}

Energy storage

Molten salts

Coupled Brayton model

Round trip efficiency

Internal and external irreversibilities

\begin{abstract}
A B S T R A C T
A thermodynamic model for a steady state pumped heat energy storage in liquid media is presented: it comprises a coupled Brayton-like heat pump and heat engine cycles connected to a cryogenic liquid and a hot molten salt by counter-flow heat exchangers. The model considers non-isothermal heat transfers between the working fluid and the liquid media and explicitly includes a set of parameters accounting for the main internal and external losses, heat leak, and pinch point effects for both the heat pump (charge) and heat engine (discharge) modes. Specific expressions for the main magnitudes in the charge (as the input power and coefficient of performance) and discharge (as power output and efficiency) modes and the global round trip efficiency have been analytically derived in terms of isentropic efficiencies of the compressor and turbine, pressure losses in the heat exchange processes, effectivenesses of the external counter-flow heat exchangers, and coupling between the working fluid and the storage and cryogenic liquid media. Round trip efficiencies around of $35-40 \%$ have been obtained, internal losses being those with main negative influence on the calculated values. The strong constraints imposed by the pinch point effects and liquid media have been analyzed. The model provides a thermodynamic assessment of the main involved processes and their interplay for a selected arrangement (molten salts, cryogenic fluid, and the charge and discharge power blocks) in order to check parametric strategies for thermodynamic optimization and design. These strategies are based on a reduced set of parameters of the overall installation and without the high computational costs of dynamical models.
\end{abstract}

\section{Introduction}

Electrical energy storage (EES) is considered as a promising technology for large-scale implementation [1] as it could improve power supply stability [2] in the power grid avoiding variability [3]. A particular type of EES is the so-called pumped heat energy storage (PHES), which in a charging process stores heat from a cold reservoir in a hot reservoir using a heat pump (HP) cycle and then, during a discharge process, heat is converted in electricity by a heat-work conversion heat engine (HE) cycle. Its independence on geographical and geological conditions suffered by most conventional pumped hydro storage and compressed air energy storage systems, motivates a high research interest nowadays [4]. Most works are focused on material selection [5], short-term storage in hybrid and intermittent energy generation systems [6], and grid storage [7]. In PHES systems usually the working fluid is a single-phase gas operating a Brayton-like cycle [8] or an appropriate fluid operating a subcritical, transcritical or organic Rankine-like cycle [9]. Also research is emphasized on thermoeconomic design optimization [10] and integration of solar and eolic resources [11]. Most thermal energy storage (TES) media are based on sensible packed-bed materials due to its wide temperature range, high efficiency and small pressure losses [8]. This kind of TES has been studied for large scale electric applications [12], using thermodynamic analysis [13] with main internal and external losses [14], parametric optimization [15], and response to cycle duration perturbations [16]. A detailed comparison in packed-bed materials using both Joule-Brayton and Rankine-like cycles was recently performed by Dietrich using exergoeconomic analyses [17].

For liquid media storage, conceptual design for cycles was first performed by Morandin et al. [9] and later applied to molten salts and synthetic oil as sensible heat storage with air as working fluid [18].

\footnotetext{
* Corresponding author.

E-mail addresses: danielsalomonegonzalez@gmail.com (D. Salomone-González), jgonzalezayala@usal.es (J. González-Ayala), pcurto@fing.edu.uy
} (P.L. Curto-Risso), anca@usal.es (A. Calvo Hernández). 


$\begin{array}{ll}\text { Nomenclature } & \\ a & \text { Temperature ratio } \\ c_{p} & \text { Specific heat capacity at constant pressure } \\ & (\mathrm{J} / \mathrm{kg} \mathrm{K}) \\ c_{v} & \text { Specific heat capacity at constant volume } \\ & (\mathrm{J} / \mathrm{kg} \mathrm{K}) \\ C & \text { Heat capacity (W/K) } \\ k & \text { Dimensionless factor }\left(\frac{\gamma-1}{\gamma}\right) \\ \dot{m} & \text { Mass flow (kg/s) } \\ P & \text { Pressure (atm) } \\ \dot{Q} & \text { Heat flow (W) } \\ r & \text { Pressure ratio } \\ T & \text { Temperature (K) } \\ W & \text { Work (W) } \\ Y & \text { Dimensionless factors } \\ Z & \text { Dimensionless factors }\end{array}$

Greek Letters

$\begin{array}{ll}\gamma & \text { Adiabatic coefficient } \\ \Gamma & \text { Dimensionless factor } \\ \epsilon & \text { Efficiencies } \\ \eta & \text { Efficiency of the heat engine } \\ \nu & \text { COP of the heat pump } \\ \xi & \text { Heat leak factor } \\ \rho & \text { Dimensionless coefficients } \\ \Phi & \text { Round trip efficiency }\end{array}$

Subscript

$\begin{array}{ll}c & \text { Compressor } \\ H & \text { High pressure } \\ L & \text { Low pressure } \\ t & \text { Turbine } \\ w & \text { Working fluid } \\ 0 & \text { Ambient }\end{array}$

Acronyms

$\begin{array}{ll}C F D & \text { Computational fluid dynamic } \\ C O P & \text { Coefficient of performance } \\ E E S & \text { Electrical energy storage } \\ H E & \text { Heat engine } \\ H P & \text { Heat pump } \\ H T H P & \text { High temperature heat pump } \\ L M T D & \text { Logarithmic mean temperature difference } \\ N T U & \text { Number of transfer units } \\ P H E S & \text { Pumped heat energy storage } \\ P P & \text { Pinch point } \\ R T E & \text { Round trip efficiency } \\ T E S & \text { Thermal energy storage }\end{array}$

Round trip efficiency (RTE) estimations around of 0.55 were reported assuming isentropic efficiencies of 0.9. Rankine-based cycles were applied to transcritical $\mathrm{CO}_{2}$ working fluid and water as TES systems [10]. With above studies as reference, Fernandez et al. [11] proposed more complex arrangements focused on the integration in a single system of renewable sources operating at different temperature levels and oriented to applications at different scales (mid/high temperature solar power plants and smaller-scale renewable installations). In this analysis, clear advantages for exploitation of synergies at different power ranges were reported. In the same line, the possibility of solar-PHES systems employing technology developed by the concentrated solar power industry was analyzed by Farres et al. [19]. The need for arrangements with intercooled stages at the cold side of the cycle was pointed out. Very recently, Frate et al. [20] reported a multi-criteria optimization analysis of a Rankine cycle with low-grade thermal energy integration using trade-off figures of merit based in layouts with and without internal regeneration in the charge and discharge operation modes. They conclude that regeneration is effective, with better global performances as it relaxes the trade-off between the objectives. Also recently, Hassan et al. [21] reported a thermodynamic analysis of a high-temperature heat pump driving an organic Rankine cycle by means of an energy storage system. The work reports latent and sensible heat for different refrigerants and configurations in order to maximize the advantages of the refrigerant subcooling.

Unlike the solid media, the liquid storage offers two additional advantages: (a) the pressure inside the tanks is independent of the pressure of the cyclic working fluid, allowing lower costs in the tanks and more compact compression and expansion devices with smaller pressure drops; and (b) the temperature inside each tank remains almost constant, avoiding the problems associated to the propagation of the hot front in solid storage. On the contrary, as noted by Laughlin [7], the main drawback relies on the need of two tanks for each reservoir, in addition to some technical requirements which must be met in order to get an appropriate integration on the overall system. Concerning to suitability of liquid media and working fluids, many work has been reported. In particular, Zaversky et al. [22] analyzed a model for the transient molten salt two-tank thermal storage, Peger et al. [23] studied the nitrate salts for sensible and latent heat storage, and cost benefits for a selection of different salts was reported by Turchi et al. [24]. For the cryogenic liquids [25], lower melting temperatures and not too high boiling temperatures at low pressure are two valuable requirements to get a wide stable liquid phase at atmospheric or sub-atmospheric pressures, as noted by Davenne et al. [26]. In what regards to the working fluid, properties of noble gases and binary mixtures on Brayton applications have been reported by Tournier and El-Genk [27] and energy and exergy analysis were conducted by Habibi et al. [28]. Also, non-toxicity and no corrosion are required conditions. Thus, potential candidates are monoatomic noble gases (specially argon (Ar) since helium ( $\mathrm{He}$ ) is quite expensive) and diatomic gases as air and nitrogen $\left(\mathrm{N}_{2}\right)$, since hydrogen $\left(\mathrm{H}_{2}\right)$ is highly inflammable [7]. Between the two usual options, argon allows higher temperature and lower pressure levels and (almost) constant heat capacity, while $\mathrm{N}_{2}$ allows the use of turbines and compressors well tested in conventional cyclic heat devices.

Methodologically, most of the models are based on computational fluid dynamic (CFD) simulations on the transient behavior [8], integration of solar energy [11] and/or commercial software through exergoeconomic analyses [17], and evaluation on thermal and mechanical performance of the hot tank [29]. Theoretical studies fully based on thermodynamic frameworks assuming Carnot-like models were conducted by Tess [30] and Chen et al. [31], while works based on weak-dissipative models were reported by Guo et al. for both pumped thermal [32] and cryogenic storage [33]. These authors also reported a recuperative Brayton-like arrangement model [34]. Optimized performance regimes were calculated.

A common characteristic of the above fully theoretical models is the assumption of constant temperature external sources. For liquid storage, this assumption is quite unrealistic as the liquid phase in the tanks changes temperature according to working fluid and heat exchanger requirements. To overcome this problem, the main goal of this paper is to formulate a novel Brayton-like arrangement for liquid storage using more realistic non-isothermal charge/discharge processes for a working fluid coupled to liquid TES by counter-flow heat exchangers, as the conceptual picture in Fig. 1 shows. The proposed model accounts for the description of both the charge and discharge 


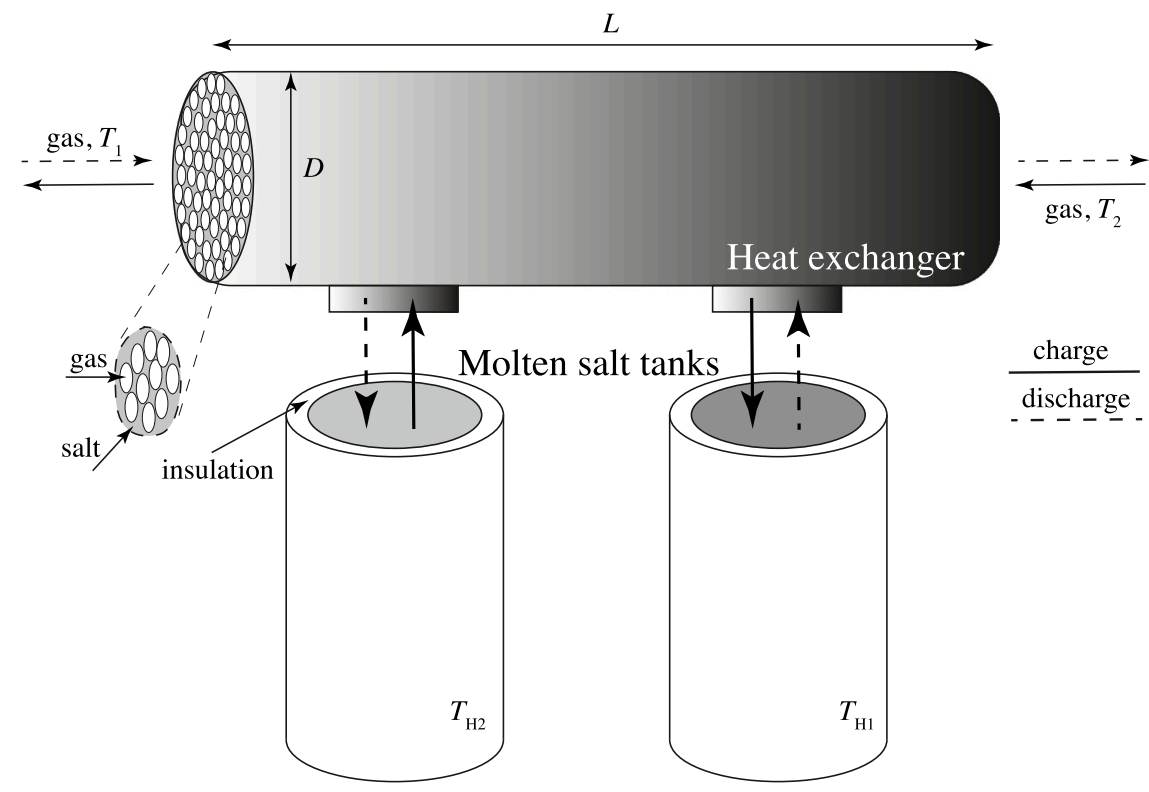

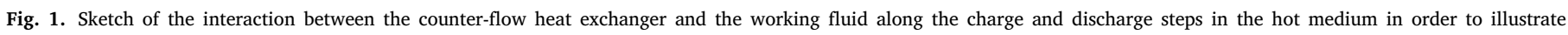
the corresponding heat transfers.

modes and their interactions with the TES system, including internal losses for compressors and expander (turbine), pressure drops for the working fluid, heat leak to the environment, external coupling of the working fluid with TES materials, and pinch point effects. It allows explicit analytical and numerical results for the main involved magnitudes as efficiency and power output of the HE cycle, the coefficient of performance (COP) and the power input of the HP cycle, and the round trip efficiency of the overall device in terms of the considered losses. From this, an additional advantage of the model is its ability to check parametric strategies for optimization and design based on a reduced set of parameters accounting for the molten salts, the cryogenic storage fluid, and the charge and discharge power blocks. In brief, it constitutes a comprehensive thermodynamic description of the main processes and their interplay for a selected arrangement without the high computational costs of dynamical models.

The paper is structured as follows. Section 2 briefly compiles some thermal properties of usual molten salts and cryogenic liquids which will be used to obtain particular numerical results. Section 3 contains the description of the HE and HP cycles as well as their coupling for the whole thermodynamic model. Section 4 shows numerical results for the efficiency of the HE, COP of the HP and overall round trip efficiency, with special emphasis on the effect of internal and external losses, heat leak, and pinch points effects. Particular examples for some systems in Table 1 are also worked out in this section to show explicit $T-S$ behaviors for HE and HP cycles, as well as to calculate specific values of the corresponding efficiency, COP, and round trip efficiency. Finally, in Section 5, discussion of the main results, some perspectives, and a brief summary are presented.

\section{Molten salts and cryogenics liquids}

Some relevant physical properties of usual molten salts [24] and standard cryogenic liquids [26] in thermal storage are compiled in Tables 1 and 2, respectively. For completeness, costs are also shown. These tables include the specific heat capacity $c_{p}$, density $\rho$, and volumetric heat capacity $\rho c_{p}$, relative to the value for solar salt. The magnitude $\rho c_{p}$ is a key factor in determining the volume of the storage liquid tanks, because of the tank size is inversely proportional to $\rho c_{p} \Delta T$. Note in Table 1 that the only molten salts with a larger volumetric heat capacity than solar salt $\left(\mathrm{NaNO}_{3} / \mathrm{KNO}_{3}\right)$ are sodium nitrate $\left(\mathrm{NaNO}_{3}\right)$ and the ternary potassium/sodium/lithium carbonate
Table 1

Some thermal properties and costs of solar salt and alternative salts for the high temperature storage, adapted from Turchi [24]. $T_{\min }$ represents the melting point or approximate liquidus point for non-eutectic salts. $T_{\max }$ the thermal stability temperature. Heat capacity $c_{p}$, density $\rho$, and volumetric heat capacity, $\rho c_{p r e l}$. All these properties are assumed as constant.

\begin{tabular}{lllllll}
\hline Salt & $\begin{array}{l}T_{\min } \\
(\mathrm{K})\end{array}$ & $\begin{array}{l}T_{\max } \\
(\mathrm{K})\end{array}$ & $\begin{array}{l}c_{p} \\
(\mathrm{~kJ} / \mathrm{kg} \mathrm{K})\end{array}$ & $\begin{array}{l}\rho \\
(\mathrm{kg} / \mathrm{l})\end{array}$ & $\rho c_{\text {prel }}$ & $\begin{array}{l}\text { Price } \\
(\mathrm{USD} / \mathrm{kg})\end{array}$ \\
\hline Solar & 511 & 858 & 1.55 & 1.71 & 1.00 & 0.80 \\
$\mathrm{NaNO}_{3}$ & 579 & 793 & 1.62 & 1.82 & 1.11 & 0.68 \\
$\mathrm{KNO}_{3}$ & 607 & 873 & 1.40 & 1.78 & 0.94 & 1.00 \\
$\mathrm{KCl} / \mathrm{MgCl}$ & 699 & $>1070$ & 1.03 & 1.94 & 0.75 & 0.35 \\
$\mathrm{MgCl} / \mathrm{NaCl} / \mathrm{KCl}$ & 658 & $>1070$ & 1.14 & 1.93 & 0.83 & 0.22 \\
$\mathrm{ZnCl}_{2} / \mathrm{NaCl}_{\mathrm{KCl}}$ & 473 & $>1070$ & 0.92 & 2.08 & 0.72 & 0.80 \\
$\mathrm{~K}_{2} \mathrm{CO}_{3} / \mathrm{Na}_{2} \mathrm{CO}_{3} /$ & 671 & 1073 & 1.79 & 2.01 & 1.36 & 2.50 \\
$/ \mathrm{Li}_{2} \mathrm{CO}_{3}$ & & & & & & \\
\hline
\end{tabular}

Table 2

Some thermal properties for the indicated cryogenic liquid storage. $T_{\min }$ denotes the melting point, $T_{\max }$ is the boiling temperature, $c_{p}$ the specific heat capacity, and $\rho$ the density (all of them assumed as constant) [25].

\begin{tabular}{llllll}
\hline Cryogenic Fluid & $\begin{array}{l}T_{\min } \\
(\mathrm{K})\end{array}$ & $\begin{array}{l}T_{\max } \\
(\mathrm{K})\end{array}$ & $\begin{array}{l}c_{p} \\
(\mathrm{~kJ} / \mathrm{kg} \mathrm{K})\end{array}$ & $\begin{array}{l}\rho \\
(\mathrm{kg} / \mathrm{l})\end{array}$ & $\begin{array}{l}\text { Price } \\
(\mathrm{USD} / \mathrm{kg})\end{array}$ \\
\hline Anhydrous ethanol & 158.8 & 351.2 & 2.46 & 0.783 & $0.43[35]$ \\
$N$-hexane & 177.9 & 342.0 & 1.65 & 0.655 & $0.70[7]$ \\
Anhydrous methanol & 175.3 & 337.5 & 2.55 & 0.787 & $0.30[19]$ \\
$N$-propane & 85.3 & 230.9 & 2.25 & 0.581 & $0.24[35]$ \\
Euthetic salt $(20 \% \mathrm{NaCl})$ & 255.6 & 376.9 & 3.11 & 1.15 & $0.50[19]$ \\
\hline
\end{tabular}

blend $\left(\mathrm{K}_{2} \mathrm{CO}_{3} / \mathrm{Na}_{2} \mathrm{CO}_{3} / \mathrm{Li}_{2} \mathrm{CO}_{3}\right)$. Solar salt shows a thermal decomposition temperature about $850 \mathrm{~K}$, which progressively increases from pure sodium nitrate and potassium nitrate $\left(\mathrm{KNO}_{3}\right)$ to binary potassium/magnesium chloride blend $\left(\mathrm{KCl} / \mathrm{MgCl}_{2}\right)$ and then for ternary combinations. For the cryogenic liquids, the liquid phase stability determined by the boiling point range is around $376 \mathrm{~K}$ for the euthetic salt and around $350 \mathrm{~K}$ for anhydrous methanol, $\mathrm{n}$-hexane, and anhydrous methanol. A smaller value of $230 \mathrm{~K}$ is presented by the $\mathrm{n}$-propane. These $T_{\min }$ (solidification temperature) and $T_{\max }$ values are very relevant as they rule the extreme temperatures of the working fluid and, as consequence, the pressure ratios of the compressor and expander. 


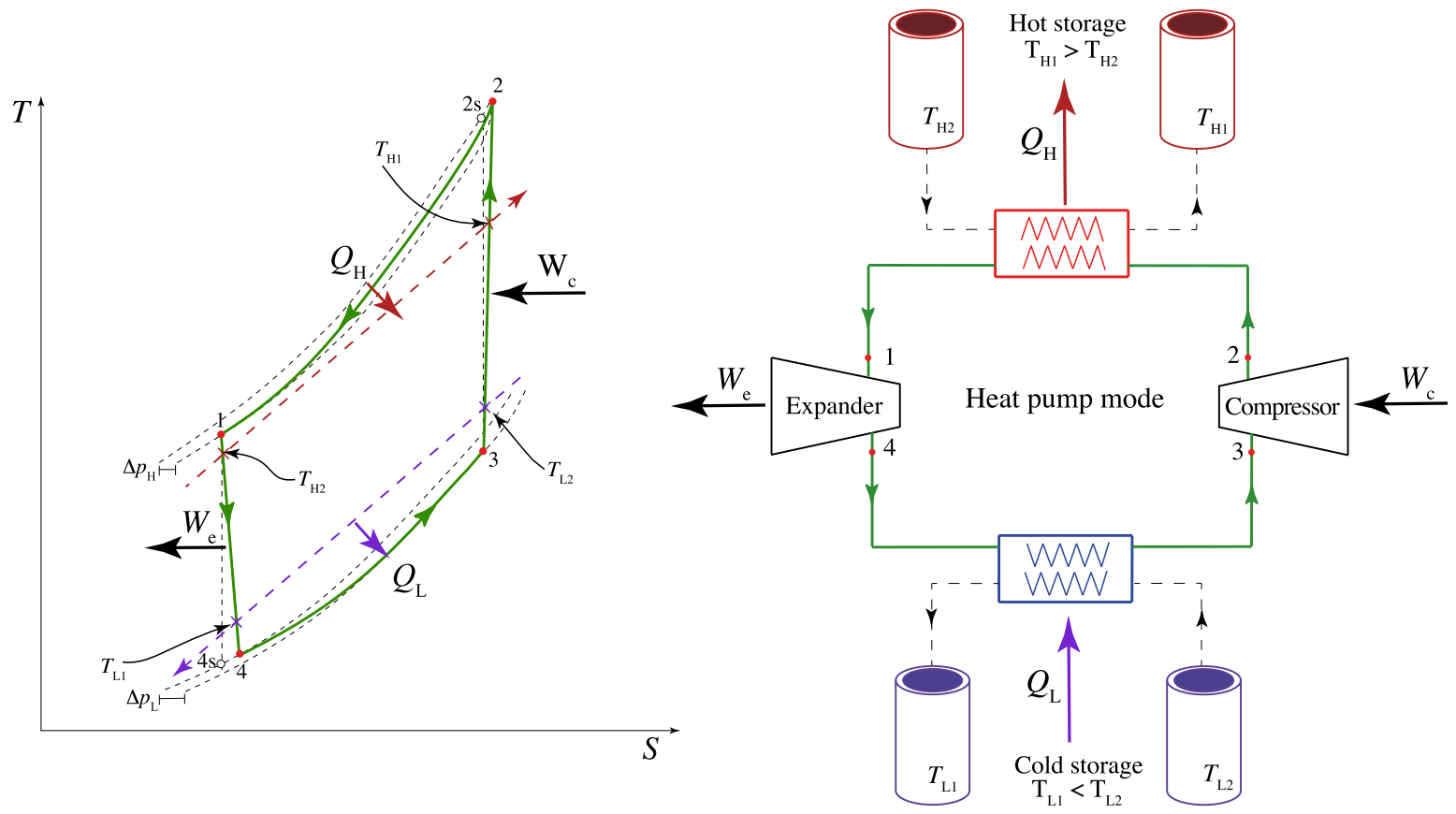

Fig. 2. (a) $T-S$ diagram of the charge HP cycle and in (b) scheme of the corresponding components.

\section{Thermodynamic model}

The proposed overall arrangement consists in a combination of a Brayton-like HP cycle followed by a Brayton-like HE cycle. Fig. 2a depicts the T-S diagram for the charge HP-cycle and Fig. $2 \mathrm{~b}$ a scheme of the corresponding components showing the interaction of the compressor and expander with the cryogenic liquid and the storage reservoir. In Fig. 3 the same is done for the discharge HE mode. A simplified $T-S$ picture of the whole PHES system is shown in Fig. 4. In both operation modes, the liquid media is stored in four tanks at different constrained temperatures, in such a way that adequate integration profiles for the charge/discharge processes holds by counter-flow heat exchangers. A brief description of the whole thermodynamic model is the following:

- Charge; Fig. 2: The working fluid enters in the HP compressor at state 3 and after a non-isentropic compression (step $3 \rightarrow 2$ ) gets its maximum pressure and maximum temperature. Then, heat rejection by the working fluid with a pressure drop $\Delta P_{H}=$ $P_{2}-P_{1}$ is used in the counter-flow heat exchanger to increase the temperature of the molten salt from $T_{H 2}$ to $T_{H 1}$ as the working fluid is cooled down along process $2 \rightarrow 1$. Next, the working fluid expands in a non-isentropic process $1 \rightarrow 4$ getting its lowest temperature and pressure. In the next step, the working fluid is slowly heated up by the heat flow coming from the cold liquid material initially at temperature $T_{L 2}$; then, the cold storage liquid diminishes its temperature to $T_{L 1}$ while the working fluid increases its temperature along step $4 \rightarrow 3$ with a pressure drop $\Delta P_{L}=P_{4}-P_{3}$, recovering the initial state at temperature $T_{3}$ and pressure $P_{3}$.

- Discharge; Fig. 3: The working fluid undergoes a non-isentropic compression $4 \rightarrow 1$; then it is heated with a pressure drop $\Delta P_{H}=$ $P_{1}-P_{2}$, across the temperature gap $T_{1}-T_{2}$ by the heat delivery in the counter-flow heat exchanger of the hot storage molten salt, which in turn decreases its temperature from $T_{H 1}$ to $T_{H 2}$. Afterwards, the hot working fluid at $T_{2}$ is expanded in the nonisentropic turbine $(2 \rightarrow 3)$, and finally, it is cooled to its initial temperature $T_{4}$ experiencing a pressure drop $\Delta P_{L}=P_{3}-P_{4}$. The heat delivered in this step by the working fluid allows the increase of temperature of the cold liquid medium from $T_{L 1}$ to $T_{L 2}$ by means of the (cold) counter-flow heat exchanger.
As detailed above, the model incorporates internal irreversibilities coming from non-isentropic expansion and compression processes in the turbine (expander) and compressor, respectively, and from pressure drops in the heater and in the cooler processes. The model also takes into account pinch point (PP) effects (see Fig. 4 and Section 4.4) and heat leaked to the environment coming from the hot molten salt (not shown in Fig. 2 and 3; see later for a mathematical description) while heat leak from the liquid cold storage is assumed to be negligible, which is a reasonable assumption at least for short operation times. After the end of HE cycle and in order to recuperate the initial conditions of the HP cycle, a heat exchanger could be necessary for process $T_{3 H E} \rightarrow T_{3 H P}$. This feature is out of the scope of this work because it is only considered steady state performance and transient behaviors are avoided.

\subsection{Thermodynamic analysis: Heat pump cycle}

The HP cycle (charging mode) with the working fluid running in an anti-clockwise direction is first considered. All specified states thus refer to Fig. 2. Pressure drops of the fluid along the hot and cold sides $\left(\Delta P_{H}\right.$ and $\Delta P_{L}$, respectively) are accounted by the coefficients $\rho_{H}$ and $\rho_{L}$, given by [36]:

$\rho_{H}=\left(\frac{P_{1}}{P_{2}}\right)^{k}=\left(\frac{P_{2}-\Delta P_{H}}{P_{2}}\right)^{k}$,
$\rho_{L}=\left(\frac{P_{3}}{P_{4}}\right)^{k}=\left(\frac{P_{4}-\Delta P_{L}}{P_{4}}\right)^{k}$,

where $k=\frac{\gamma-1}{\gamma}$ and $\gamma=c_{p} / c_{V}$ is the adiabatic coefficient of the working fluid. It is common to account for internal losses at the compressor and turbine using isentropic efficiencies for the compression and expansion processes, $\epsilon_{c}$ and $\epsilon_{t}$, respectively, given by [37]:

$\epsilon_{c}=\frac{T_{2 s}-T_{3}}{T_{2}-T_{3}}$

$\epsilon_{t}=\frac{T_{1}-T_{4}}{T_{1}-T_{4 s}}$

where $T_{2 s}$ and $T_{4 s}$ refer to isentropic processes. The variables $a_{c}$ and $a_{t}$ are defined in terms of the compression ratios, $r_{c} \equiv P_{2} / P_{3}$ for the 




Fig. 3. (a) $T-S$ diagram of the discharge HE cycle and in (b) scheme of the corresponding components.

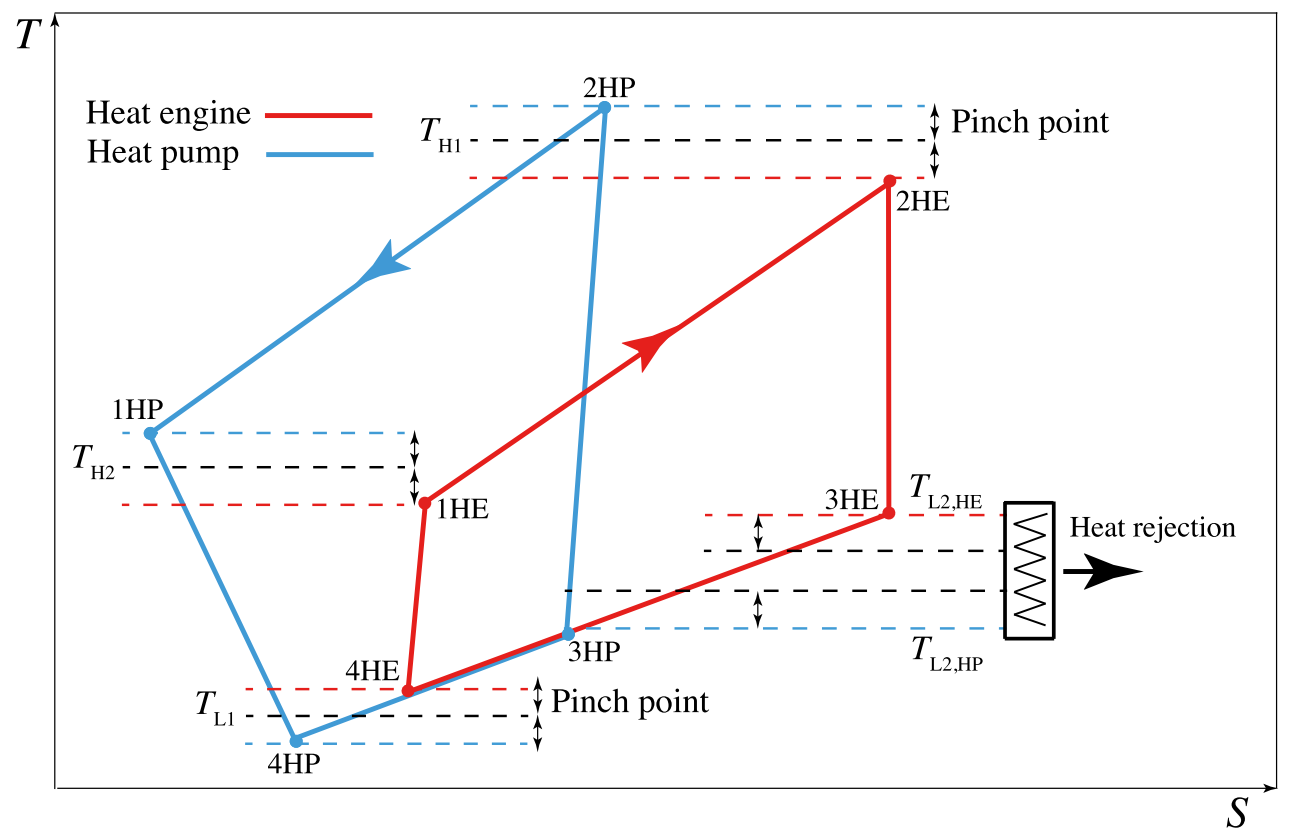

Fig. 4. $T-S$ setup of the whole thermodynamic cycle for the PHES system.

compressor and $r_{t} \equiv P_{1} / P_{4}$ for the expander (turbine). They are given as:

$a_{c}=\frac{T_{2 s}}{T_{3}}=r_{c}^{k}=\left(\frac{P_{2}}{P_{3}}\right)^{k}=\left(\frac{P_{2}}{P_{4}-\Delta P_{L}}\right)^{k}$,

$a_{t}=\frac{T_{1}}{T_{4 s}}=r_{t}^{k}=\left(\frac{P_{1}}{P_{4}}\right)^{k}=\left(\frac{P_{2}-\Delta P_{H}}{P_{4}}\right)^{k}$.

According to Eqs. (1) and (2), $a_{t}$ and $a_{c}$ are linked by the relation

$a_{t}=\rho_{H} \rho_{L} a_{c}$.
The input power on the working fluid by the compressor $W_{c}$ and the power output $W_{t}$ in the expander (turbine) are:

$W_{c}=C_{w}\left(T_{2}-T_{3}\right)=C_{w} T_{3}\left(\frac{a_{c}-\left(1-\epsilon_{c}\right)}{\epsilon_{c}}\right)$,

and

$W_{t}=C_{w}\left(T_{1}-T_{4}\right)=C_{w} T_{1} \epsilon_{t}\left(\frac{a_{t}-1}{a_{t}}\right)$,

where $C_{w}\left(\equiv \dot{m}_{w} c_{p w}\right)$ is the per-unit-time heat capacity of the working fluid.

The irreversible heat transfers between the working fluid and the external liquid storages take place along temperature dependent processes 
as the heat capacities remain finite. Then, the liquid materials change temperature along the counter-flow exchangers with the working fluid. The temperatures of the working fluid along $2 \rightarrow 1$ should be greater than the high-temperature thermal energy storage system (the molten salts) at $T_{H 1}$, so that an amount of heat, $\dot{Q}_{H}$, is absorbed by the salt reservoir which increase its temperature from $T_{H 2}$ to $T_{H 1}$. Opposite, the temperatures of the working fluid along $4 \rightarrow 3$ should be smaller than the low-temperature thermal energy storage, so that an amount of heat, $\dot{Q}_{L}$, is delivered as the temperature decreases from $T_{L 2}$ to $T_{L 1}$.

The corresponding heat transfers can be properly taken into account by using the logarithmic mean temperature difference (LMTD) [38] between the hot and cold feeds at each end of the counterflow exchanger or by using the Number of Transfer Units (NTU) method [39]. Here, and in order to avoid very specific technical details, it is assumed an usual treatment of finite time thermodynamics in which the heat rate of the working fluid $C_{w}\left(T_{2}-T_{1}\right)$ and the heat rate in the hot side of the counterflow heat exchangers $C_{H}\left(T_{H 1}-T_{H 2}\right)$ are balanced through a global effectivenesses $\epsilon_{H}$. In the same way the heat rate of the working fluid $C_{w}\left(T_{3}-T_{4}\right)$ and the heat rate in the cold side of the counterflow heat exchangers $C_{L}\left(T_{L 2}-T_{L 1}\right)$ are balanced through a global effectivenesses $\epsilon_{L}$ [38]. Then $\dot{Q}_{H}$ and $\dot{Q}_{L}$ can be written as:

$\dot{Q}_{H}=C_{w}\left(T_{2}-T_{1}\right)=C_{H}\left(T_{H 1}-T_{H 2}\right)=C_{H, \min } \epsilon_{H}\left(T_{2}-T_{H 2}\right)$,

and

$\dot{Q}_{L}=C_{w}\left(T_{3}-T_{4}\right)=C_{L}\left(T_{L 2}-T_{L 1}\right)=C_{L, \min } \epsilon_{L}\left(T_{L 2}-T_{4}\right)$,

where $C_{w}$ is the heat capacity of the working fluid and $C_{H, \min }=$ $\min \left(C_{H}, C_{w}\right)$ and $C_{L, \min }=\min \left(C_{L}, C_{w}\right)$ are the minimal heat capacities of the hot and cold TES media, respectively.

By combining the above equations it is obtained that:

$T_{H 1}=T_{H 2}+\Gamma_{H}\left(T_{2}-T_{1}\right)$

and

$T_{L 1}=T_{L 2}-\Gamma_{L}\left(T_{3}-T_{4}\right)$,

where $\Gamma_{H}=\frac{C_{W}}{C_{H}}$ and $\Gamma_{L}=\frac{C_{W}}{C_{L}}$. These equations play an important role as they link the salt temperatures of the hot tanks $\left(T_{H 1}\right.$ and $\left.T_{H 2}\right)$ an of the cryogenic liquid $\left(T_{L 1}\right.$ and $\left.T_{L 2}\right)$ with the temperatures of the working fluid in the extreme states of the HP cycle in terms of dimensionless coefficients $\Gamma_{H}$ and $\Gamma_{L}$.

The outlet temperatures in the compressor, $T_{2}$, and expander, $T_{4}$, can be worked out in terms of the isentropic efficiencies $\left(\epsilon_{c}\right.$ and $\left.\epsilon_{t}\right)$, pressure losses $\left(\rho_{H}\right.$ and $\left.\rho_{L}\right)$, and effectivenesses $\left(\epsilon_{H}\right.$ and $\left.\epsilon_{L}\right)$. By using Eqs. (3), (4), (7), (12) and (13), $T_{1}, T_{2}, T_{3}, T_{4}$ and also $T_{H 1}$ and $T_{L 1}$ can be expressed in terms of $T_{H 2}$ and $T_{L 2}$. The reason for selecting these temperatures is due to practical purposes: $T_{L 2}$ is the starting temperature of the cryogenic fluid in the charging process and can be fixed to a certain value, for example, the environment temperature, and $T_{H 2}$ is the temperature in the salt tank (obviously, greater than the melting point of the salt) at the beginning of the charge cycle. The relevant temperatures of the HP cycle are given by:

$T_{1}=\frac{T_{H 2} \epsilon_{H}+T_{L 2} Z_{1} \epsilon_{L}\left(1-\epsilon_{H}\right)}{1-Z_{1} Z_{2}\left(1-\epsilon_{H}\right)\left(1-\epsilon_{L}\right)}$,

$T_{3}=\frac{T_{L 2} \epsilon_{L}+T_{H 2} Z_{2} \epsilon_{H}\left(1-\epsilon_{L}\right)}{1-Z_{1} Z_{2}\left(1-\epsilon_{H}\right)\left(1-\epsilon_{L}\right)}$,

$T_{2}=T_{3} Z_{1}$,

$T_{4}=T_{1} Z_{2}$,

with $a_{t}=\rho_{H} \rho_{L} a_{c}$, as mentioned before, and

$Z_{1} \equiv \frac{a_{c}-\left(1-\epsilon_{c}\right)}{\epsilon_{c}}, \quad Z_{2} \equiv \frac{a_{t}\left(1-\epsilon_{t}\right)+\epsilon_{t}}{a_{t}}$.

The COP of the HP cycle, $v \equiv \dot{Q}_{H} /\left(\dot{Q}_{H}-\dot{Q}_{L}\right)$, is given by:

$v=\frac{Z_{2}\left(\frac{1-\epsilon_{L}}{\epsilon_{L}}\right)-\frac{1}{Z_{1} \epsilon_{L}}+\frac{T_{L 2}}{T_{H 2}}}{Z_{2}\left(\frac{1-\epsilon_{L}}{\epsilon_{L}}+\frac{T_{L 2}}{T_{H 2}} \frac{1-\epsilon_{H}}{\epsilon_{H}}\right)+\frac{Z_{2}}{Z_{1}}-\frac{1}{Z_{1}}\left(\frac{1}{\epsilon_{H}}+\frac{1}{\epsilon_{L}}\right)+\frac{T_{L 2}}{T_{H 2}}}$.
Another irreversibility source is the unavoidable heat leak between the hot and cold sides of the overall plant. A detailed analysis of this point should include separately the charge and discharge modes, the interactions of the working fluid with the liquid media, the cycle time and, most important, the materials, sizing, and geometry of the salts tanks. Such analysis is out of the scope of this work. Here, it will be assumed only a heat leak between the molten salt sources $T_{H 1}$ and $T_{H 2}$ with the environment at temperature $T_{0}$, and a negligible heat leak due to the cold liquid storage. In the finite-time-thermodynamics framework an easy way to take into account this effect is by assuming an averaged, linear decreasing of the temperatures $T_{H 1}$ y $T_{H 2}$ with an effective proportionality factor $\xi$, so that the initial temperatures $T_{H 1}$ y $T_{H 2}$ decreases due to heat leak as:

$\Delta T_{H 1}=-\xi\left(T_{H 1}-T_{0}\right)$,

$\Delta T_{H 2}=-\xi\left(T_{H 2}-T_{0}\right)$.

This linear assumption has been corroborated by empirical results in the analysis of heat losses in two-tank thermal storage systems for concentrated solar power plants [40].

\subsection{Thermodynamic analysis: Heat engine cycle}

For the HE case all subscripts and processes refer to Fig. 3. The pressure drops of the working fluid in the hot (low) sides, $\rho_{H}\left(\rho_{L}\right)$, are defined as:

$\rho_{H}=\left(\frac{P_{2}}{P_{1}}\right)^{k}=\left(\frac{P_{1}-\Delta P_{H}}{P_{1}}\right)^{k}$,
$\rho_{L}=\left(\frac{P_{4}}{P_{3}}\right)^{k}=\left(\frac{P_{3}-\Delta P_{L}}{P_{3}}\right)^{k}$.

The internal losses for the compressor and turbine processes are quantified through the corresponding isentropic efficiencies, $\epsilon_{c}$ and $\epsilon_{t}$, respectively:

$\epsilon_{c}=\frac{T_{1 s}-T_{4}}{T_{1}-T_{4}}$

$\epsilon_{t}=\frac{T_{2}-T_{3}}{T_{2}-T_{3 s}}$.

The isentropic pressure ratios for the turbine, $r_{t}$, and compressor, $r_{c}$, are given now by the relations $r_{c} \equiv P_{1} / P_{4}$ and $r_{t} \equiv P_{3} / P_{2}$ and the corresponding $a_{c}$ and $a_{t}$ are now

$a_{c}=\frac{T_{1 s}}{T_{4}}=r_{c}^{k}=\left(\frac{P_{1}}{P_{4}}\right)^{k}=\left(\frac{P_{1}}{P_{3}-\Delta P_{L}}\right)^{k}$,

$a_{t}=\frac{T_{2}}{T_{3 s}}=r_{t}^{k}=\left(\frac{P_{2}}{P_{3}}\right)^{k}=\left(\frac{P_{1}-\Delta P_{H}}{P_{3}}\right)^{k}$,

which are linked by the same relation than in the HP cycle

$a_{t}=\rho_{H} \rho_{L} a_{c}$.

In the HE mode the high temperature liquid store decreases its temperature from $T_{H 1}$ to $T_{H 2}$ as the working fluid temperature increases from $T_{1}$ to $T_{2}$ while absorbing heat through the heat exchanger. Opposite to this, the low temperature store increases its temperature from $T_{L 1}$ to $T_{L 2}$ as the working fluid temperature decreases from $T_{3}$ to $T_{4}$ while delivering heat through the heat exchanger. As for the HPcycle, these heat transfers can be written in terms of the effectivenesses as:

$\dot{Q}_{H}=C_{w}\left(T_{2}-T_{1}\right)=C_{H}\left(T_{H 1}-T_{H 2}\right)=C_{H, \min } \epsilon_{H}\left(T_{H 1}-T_{1}\right)$,

and

$\dot{Q}_{L}=C_{w}\left(T_{3}-T_{4}\right)=C_{L}\left(T_{L 2}-T_{L 1}\right)=C_{L, \min } \epsilon_{L}\left(T_{3}-T_{L 1}\right)$,

which link the temperatures of the hot tanks $\left(T_{H 1}\right.$ and $\left.T_{H 2}\right)$ and the cryogenic liquid $\left(T_{L 1}\right.$ and $\left.T_{L 2}\right)$ with the temperatures of the working fluid in the extreme states of the HE cycle. From the above equations, 
the temperatures of the salt tanks $\left(T_{H 2}, T_{H 1}\right)$ and of the cryogenic liquid $\left(T_{L 2}\right.$ and $T_{L 1}$ ) in terms of the corresponding dimensionless coefficients $\Gamma_{H}$ and $\Gamma_{L}$ are given as:

$T_{H 2}=T_{H 1}-\Gamma_{H}\left(T_{2}-T_{1}\right)$,

and

$T_{L 2}=T_{L 1}+\Gamma_{L}\left(T_{3}-T_{4}\right)$,

with $\Gamma_{H}=\frac{C_{W}}{C_{H}}$ and $\Gamma_{L}=\frac{C_{W}}{C_{J}}$. As for the HP mode, in the above equations $C_{w}$ is the heat capacity of the working fluid and $C_{H, \min }$ and $C_{L, \min }$ are the minimal heat capacities of the hot and cold TES media, respectively.

By using Eqs. (24), (25), and (28), $T_{1}, T_{2}, T_{3}, T_{4}, T_{H 2}$ and $T_{L 2}$ can be expressed in terms of $T_{H 1}$ and $T_{L 1}$. The explicit expressions are given by

$T_{2}=\frac{T_{H 1} \epsilon_{H}+T_{L 1} Y_{1} \epsilon_{L}\left(1-\epsilon_{H}\right)}{1-Y_{1} Y_{2}\left(1-\epsilon_{H}\right)\left(1-\epsilon_{L}\right)}$,

$T_{4}=\frac{T_{L 1} \epsilon_{L}+T_{H 1} Y_{2} \epsilon_{H}\left(1-\epsilon_{L}\right)}{1-Y_{1} Y_{2}\left(1-\epsilon_{H}\right)\left(1-\epsilon_{L}\right)}$,

$T_{1}=T_{4} Y_{1}$,

$T_{3}=T_{2} Y_{2}$,

where

$Y_{1} \equiv \frac{a_{c}-\left(1-\epsilon_{c}\right)}{\epsilon_{c}}, \quad Y_{2} \equiv \frac{a_{t}\left(1-\epsilon_{t}\right)+\epsilon_{t}}{a_{t}}$,

and $a_{t}=a_{c} \rho_{H} \rho_{L}$. From the above equations, the efficiency of the Brayton heat engine in the discharge phase, $\eta=\dot{W}_{\text {out }} / \dot{Q}_{H}=\left(\dot{Q}_{H}-\right.$ $\left.\dot{Q}_{L}\right) / \dot{Q}_{H}$, is given as:

$\eta=1+\frac{T_{L 1} \epsilon_{L}\left(Y_{1} Y_{2}\left(1-\epsilon_{H}\right)-1\right)+T_{H 1} Y_{2} \epsilon_{H} \epsilon_{L}}{T_{H 1} \epsilon_{H}\left(Y_{1} Y_{2}\left(1-\epsilon_{L}\right)-1\right)+T_{L 1} Y_{1} \epsilon_{H} \epsilon_{L}}$.

For the heat leak, the treatment is as for the HP cycle. Thus, only the heat leak between the molten salt source and the ambient with temperature $T_{0}$ will be considered assuming a negligible heat leak due to the coupling of the cold liquid storage. As a consequence, a linear decreasing of the temperatures $T_{H 1}$ y $T_{H 2}$ with a proportionality factor $\xi$ is considered:

$\Delta T_{H 1}=-\xi\left(T_{H 1}-T_{0}\right)$,

$\Delta T_{H 2}=-\xi\left(T_{H 2}-T_{0}\right)$.

\subsection{Overall performance}

A sketch of the $T$ - $S$ diagram of both HP and HE cycles is depicted in Fig. 4 . Notice that there is a difference in temperature between the starting point of the HP (label 3HP) and the ending point of the HE cycle (label 4HE). This should be considered in order to couple both cycles since a decrease in temperature is needed to pass from charge to discharge. The overall performance of the PHES system is defined in terms of the steady-state round trip efficiency [8], $\Phi$, as the ratio between power generated in the heat engine $\dot{W}_{\text {out }}^{H E}$ and power input in the heat pump $\dot{W}_{n e t}^{H P}$. Considering both magnitudes as positive $\Phi$ is given as:

$\Phi=\frac{\text { net power output }}{\text { net power } \text { input }}=\frac{\dot{W}_{\text {out }}^{H E}}{\dot{W}_{\text {net }}^{H P}}=\frac{\eta \dot{Q}_{H}^{H E}}{v^{-1} \dot{Q}_{H}^{H P}}$

where the last equality follows from the usual definitions of the efficiency $\eta=\dot{W}_{n e t}^{H P} / \dot{Q}_{H}^{H E}$ in terms of the heat rate absorbed by the heat engine and of the COP, $v=\dot{Q}_{H}^{H P} / \dot{W}_{n e t}^{H P}$, in terms of the heat rate exchanged in the condenser in the heat pump operation.

\section{Results}

From the model in the previous section, it is evident that any particular configuration performance needs the specification of a set of variables and parameter for both the HE and HP cycles as well as the constraints imposed by the liquid media. These points are considered below. Next, a general overview is done on the basis of each type of irreversibility, and finally, some concrete results are given for some molten salts and cryogenics liquids in Tables 1 and 2 .

\subsection{Parameters and constraints}

The compression ratios, $r_{c}^{H E}$ and $r_{c}^{H P}$, are the fundamental independent variables. But also the model incorporates a set of parameter accounting for: (a) internal irreversibilities (the isentropic efficiencies of the compressor and turbine $\left(\epsilon_{c}, \epsilon_{t}\right)$ and the pressure drops in the high and low temperature sides $\left(\rho_{H}, \rho_{L}\right)$ ); (b) external irreversibilities by means of one additional parameter for the heat leak in the hot tanks $(\xi)$ and two parameters for the coupling of the working fluid to the relevant external thermal energy storage $\left(\epsilon_{H}, \epsilon_{L}\right)$; and (c) one more parameter describing the nature of the working fluid $(\gamma)$.

Concerning with the TES liquid media temperatures, some restrictions should be taken into account to keep the liquid nature of the salt and of the cryogenic medium. These features impose some corresponding bounds in the values of $T_{H 1}, T_{H 2}, T_{L 1}$, and $T_{L 2}$. So, according with values in Tables 1 and 2, it is considered here that: (a) in average the maximum temperature of the salt medium is $T_{\max \text {,salt }}=1200 \mathrm{~K} \geq$ $T_{H 1}^{H P}=T_{H 1}^{H E}$; (b) in average the minimum temperature of the salt medium is $T_{\text {min,salt }}=480 \mathrm{~K} \leq T_{\mathrm{H} 2}$; (c) in average the maximum temperature of the cryogenic liquid is $T_{\max , c r y}=350 \mathrm{~K} \geq T_{L 2}$; and (d) in average the minimum temperature of the cryogenic medium is $T_{\text {min, } \text { rry }}=85 \mathrm{~K} \leq T_{L 1}$.

Another key influence is played by the heat capacities which balance the heat transfers between the working fluid and the TES liquid media, as shown in Eqs. (12) and (13) for the HP-cycle and Eqs. (31) and (32) for the HE-cycle. Accordingly, dimensionless coefficients $\Gamma_{H}^{H E}=C_{w} / C_{H} \leq 1, \Gamma_{L}^{H E}=C_{w} / C_{L} \leq 1$ for the discharging mode and $\Gamma_{H}^{H P}=C_{w} / C_{H} \leq 1, \Gamma_{L}^{H P}=C_{w} / C_{L} \leq 1$ for the charging cycle are assumed. This assumption may require the fitting of the mass flow rate of the liquids according to $\Gamma=C_{w} / C_{H, L}=\left(\dot{m} c_{p}\right)_{w} /\left(\dot{m} c_{p}\right)_{H, L} \leq 1$.

The pinch point (PP) effects, minimum temperature difference between hot and cold streams within heat exchanger in the heat transfer process can be assumed as a compromise between rate and efficiency of the heat exchange and plays an important role in the heat transfer process in the counter flow heat exchangers. Here, the PP-effects at the ends of the heat exchangers will be considered as a further approach to real systems [41].

\subsection{General overview}

The theoretical model in the last section has been implemented in Mathematica programming language, and the numerical results are presented below. For the sake of simplicity it is assumed that the parameters of the same nature have the same value in both charge and discharge cycles: $\epsilon_{c}^{H P}=\epsilon_{c}^{H E}, \epsilon_{t}^{H P}=\epsilon_{t}^{H E}, \epsilon_{H}^{H P}=\epsilon_{H}^{H E}, \epsilon_{L}^{H P}=\epsilon_{L}^{H E}$, $\Delta P_{H}^{H P}=\Delta P_{L}^{H P}=\Delta P_{H}^{H E}=\Delta P_{L}^{H E}=\Delta P$. As reference values in the baseline arrangement, and in agreement with usual reported values for these HE [36] and HP [38] cycles and optimization analysis [42], the following values of parameters are assumed: $\epsilon_{c}=\epsilon_{t}=0.9, \epsilon_{H}=\epsilon_{L}=$ $0.90, \Delta P=0.02 P_{i}$, where $P_{i}$ is the pressure at the beginning of each process, and $\xi=0.02$. All calculations below are presented in terms of the compression ratio of the HE-cycle, $r_{c}^{H E}$ and of the HE-cycle, $r_{c}^{H P}$ with input values of $T_{H 2}^{H P}=500 \mathrm{~K}, T_{L 2}^{H P}{ }^{c}=T_{0}=300 \mathrm{~K}, T_{L 1}^{H E}=250 \mathrm{~K}$, and $P_{4}=1 \mathrm{~atm}$. for an ideal diatomic gas as working fluid $\gamma=1.4$.

Fig. 5 shows the behavior of efficiency, $\eta$, coefficient of performance, $v$, and round trip efficiency, $\Phi$, in terms of compression ratios 

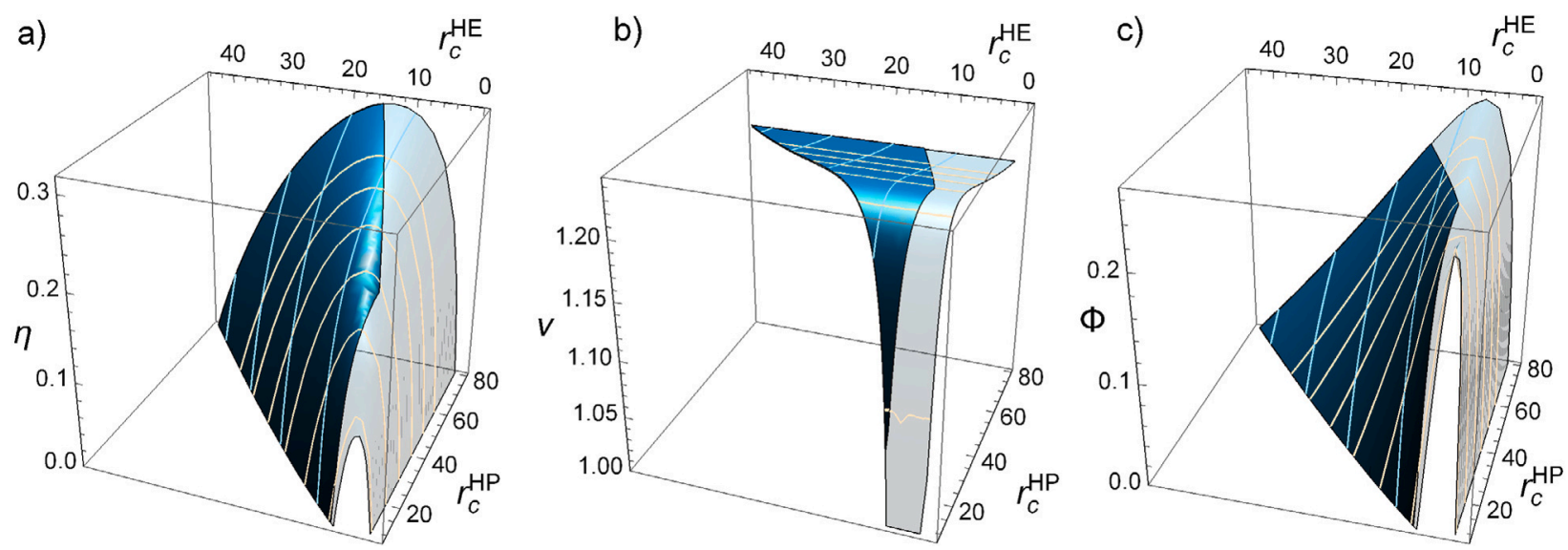



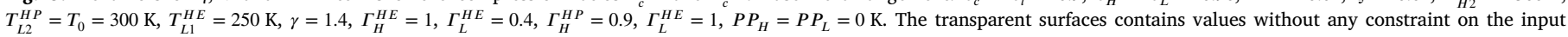
parameters.
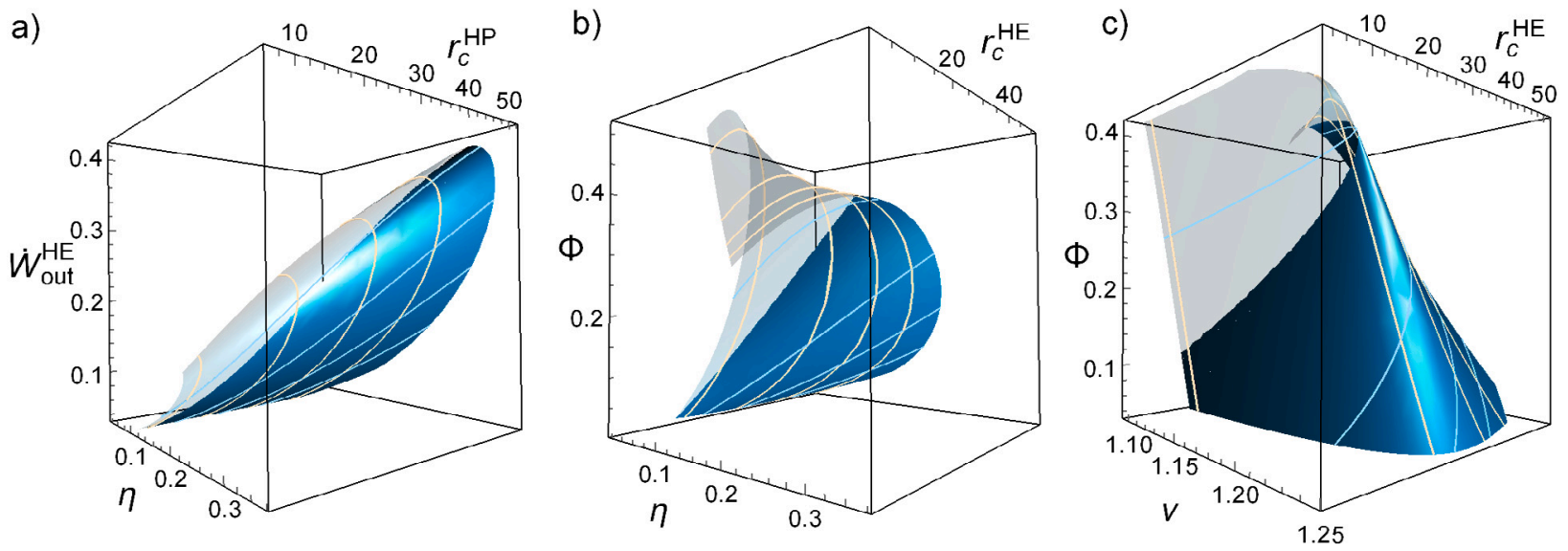


is as in previous figure.

$r_{c}^{H E}, r_{c}^{H P}$ and for the specified parameter values. The transparent surfaces correspond to unsuitable values according to constraints in the temperatures of the liquid media and pinch point effects. Probably the most important point to be noted is that there are noticeable limitations in the $r_{c}^{H E}$ and $r_{c}^{H P}$ values, so that lower $r_{c}$-values for the HE-cycle and, specially for the HP-cycle, are not suitable according to the imposed constraints. Also note the non-trivial behaviors of the efficiency in the HE cycle and of the COP in the HP cycle: roughly speaking, it is noted as in the charging mode (see Fig. 5b) the highest COP values are restricted for high $r_{c}^{H E}$ and $r_{c}^{H P}$ values while in the discharge model high efficiency values are obtained for smaller $r_{c}^{H E}$ values. Altogether makes that the resulting round trip efficiency, $\Phi$, inside the allowed $r_{c}$ range, shows a non trivial behavior but getting maximum values at moderate $r_{c}^{H E}$ values (see Fig. 5c).

The above results and trends can be seen in a complementary way by the parametric elimination of the $r_{c}^{H P}$ variable. These results are shown in Fig. 6 for the power output $\stackrel{c}{W}_{\text {out }}^{H E}$ versus efficiency $\eta$ of the HE-cycle (Fig. 6a), for the round trip efficiency $\Phi$ versus $\eta$ (Fig. 6b), and for $\Phi$ versus $v$ (Fig. 6c). It is specially important to note the strong constraints experienced by the parameters (solid colors) at high compression ratios when faced with those without any restrictions (transparent surfaces). This provokes the disappearance of well-known behaviors when the HE cycle or the HP cycle work alone. For instance, the typical loop-like plots of the power output versus the efficiency in a HE cycle are only visible here in a small range of $r_{c}^{H P}$ values (see Fig. 6a).

\subsection{Internal and external irreversibility effects}

The general configuration in Figs. 5 and 6 are amenable for discussing in detail the influence of irreversibility sources, both those affecting the internal $\left(\epsilon_{c}, \epsilon_{t}, \rho_{H}, \rho_{L}\right)$ and external losses $\left(\epsilon_{H}, \epsilon_{L}, \xi\right)$ as well as the PP effects. Instead of presenting particular results for each irreversibility parameter, a generic and global overview for each kind of irreversibility is shown. So, Fig. 7 displays the effects of the internal irreversibilities and Fig. 8 shows the effects of the external irreversibilities. From these figures, the following main general results can be pointed out:

(a) As the irreversibilities increase (in the order green, blue, and red in Figs. 7 and 8), the physical arrangements are strongly restricted due to the progressively small range of values for the compression ratios of the HE and HP. This feature provokes the progressive disappearance of the well-known loop-like behaviors for $\eta$ versus $r_{c}^{H E}$ and $v$ versus $r_{c}^{H P}$, clearly visible in the most reversible configurations (green colors). Thus, the round trip efficiency values are smaller (below 0.4 in all cases) and only for very particular values of the HP and HE compression ratios.

(b) When comparing the effects of the internal (Fig. 7) and external (Fig. 8) losses, the above trends are the same but, in the case of internal irreversibilities the effects are much greater (note the different vertical scales of these figures).

A complementary view to see the influence of the losses is to focus on the parametric behavior of magnitudes $\eta, v$, and $\Phi$ by the elimination of the $r_{c}^{H P}$. This is shown in Fig. 9 for the internal irreversibilities 
a)

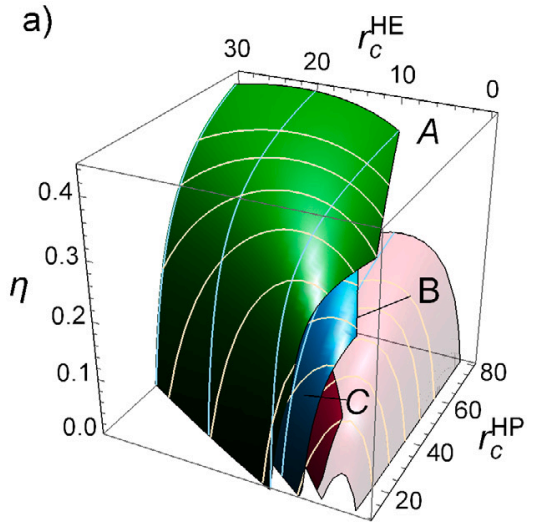

d)



b)



e)

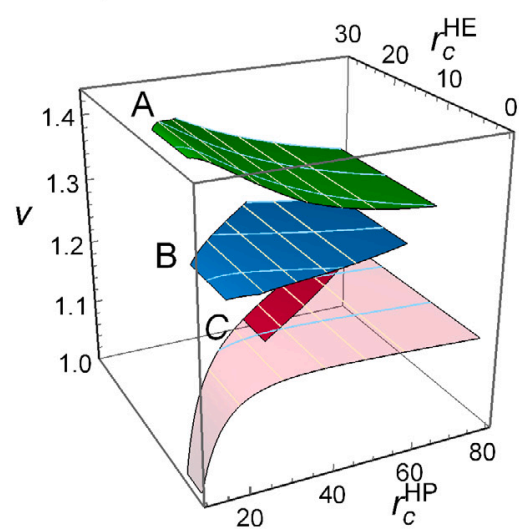

c)

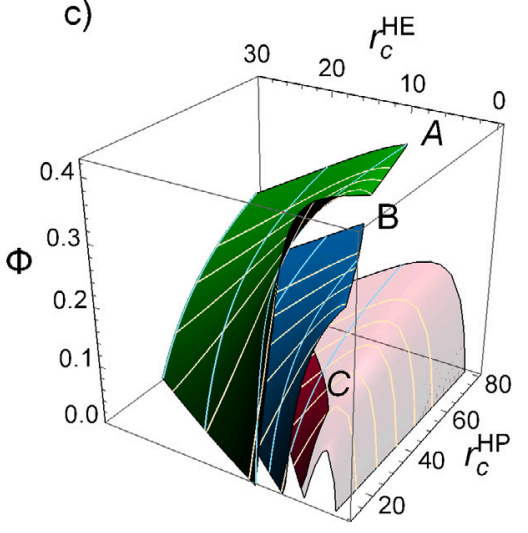

f)

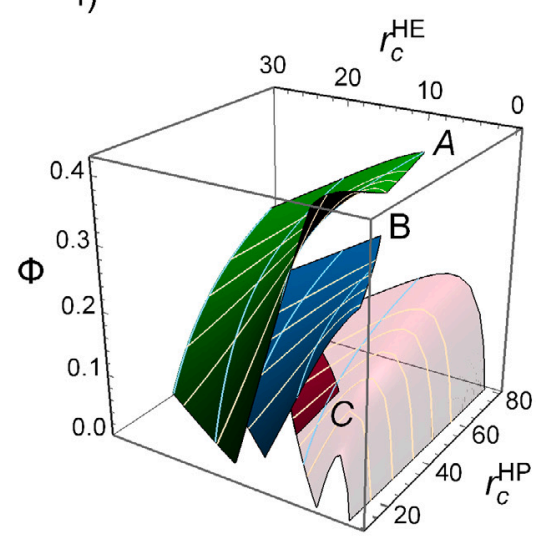

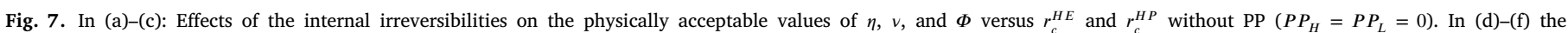



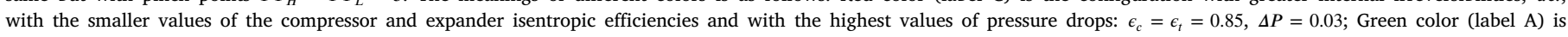

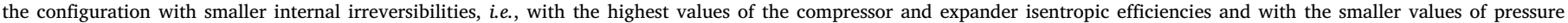

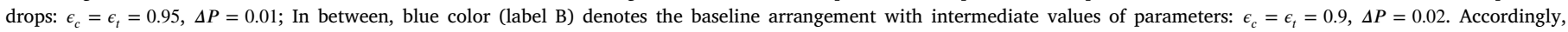


then for the intermediate reversible configuration (B, blue color), and the smaller values correspond to the most irreversible configuration (C, red color).

and in Fig. 10 for the external ones. Note here that the different surfaces $\Phi-\eta$ and $\Phi-v$ are clearly separated according to the $r_{c}^{H E}$-values. This feature is more visible in the $\Phi-v$ space of the internal losses.

\subsection{Pinch points effects}

When comparing PP effects (lower panel in Fig. 7 for internal losses and lower panel in Fig. 8 for external losses) the general trend of $\eta, \nu$, and $\Phi$ still remains the same but is it is very clear that the PP requirements play a key role reducing even more the range of acceptable compression ratios $r_{c}^{H E}$ and $r_{c}^{H P}$ without appreciable change in the numerical values of the magnitudes. It is noteworthy the strong constraints on the $r_{c}^{H P}$ values as they rule on the outlet temperature of the working fluid in the HP compressor which should satisfy the $P P_{H}$ condition in regards to the temperature of the molten salt in the hot tank $T_{H 1}$ and in the cold tank $T_{H 2}$. Similar considerations apply to the $P P_{L}$ condition in regards to the temperature of the cryogenic liquid in the cold tanks $T_{L 1}$ and $T_{L 2}$. This feature is illustrated with more details in the next particular cases.

\subsection{Particular configurations}

This subsection is intended to show particular configurations with closer approach to check the theoretical predictions for representative molten salts listed in Table 1 and with methanol as cryogenic liquid in all cases.
In the first example, solar salt it is considered in the hot TES and argon as working fluid $\left(\gamma=1.667, c_{p w}=0.52 \mathrm{~kJ} / \mathrm{kg} \mathrm{K}\right)$ with dimensionless coefficients $\Gamma_{H}^{H E}=C_{w} / C_{H}=1, \Gamma_{L}^{H E}=C_{w} / C_{L}=0.35$, $\Gamma_{H}^{H P}=C_{w} / C_{H}=1$, and $\Gamma_{L}^{H P}=C_{w} / C_{L}=0.35$. The salt temperatures are in the range $511-858 \mathrm{~K}$ and the temperatures of the cryogenic liquids in the range $175-351 \mathrm{~K}$. The same standard values are elected for irreversibility parameters (see caption in Table 3 ).

The results of the model are plotted in Fig. 11 where the HP and HE cycles are depicted in the $T-S$ diagram together with the temperature $T_{H 1}, T_{H 2}, T_{L 1}$, and $T_{L 2}$. These temperatures and those of each state are collected together with the theoretical values of $\eta, v$ and $\Phi$ in Table 3 . Also, it is plotted the physically acceptable parameter space of the $r_{c}^{H E}$ and $r_{c}^{H P}$ values according to the input data and characteristics of the solar salt, working fluid, and cryogenic liquid. The red star denote the exact value of $r_{c}^{H E}$ and $r_{c}^{H P}$ in the charge and discharge modes for the particular arrangement. Fig. 12 and Table 4 contain the results for the same system but now the working fluid is air with $\gamma=1.4$ and $c_{p w}=1.14$ $\mathrm{kJ} / \mathrm{kg} \mathrm{K}$. Comparing with results in Fig. 11, it should be stressed the higher compression ratios needed to keep the temperature levels along the cycles, specially in the HP-mode together with the higher $S$-values (note the different scales of the horizontal axes). Also note that the $\eta$, $\nu$, and $\Phi$ results are essentially the same.

Fig. 13 and Table 5 show the results for the carbonate salt in argon $\left(\gamma=1.667, c_{p w}=0.52 \mathrm{~kJ} / \mathrm{kg} \mathrm{K}\right)$. Note that in this case the minimum and maximum temperatures for the salt are, respectively, $671 \mathrm{~K}$ and 1.073 $\mathrm{K}$. As a consequence, compared with the argon-solar salt case, it should 
a)

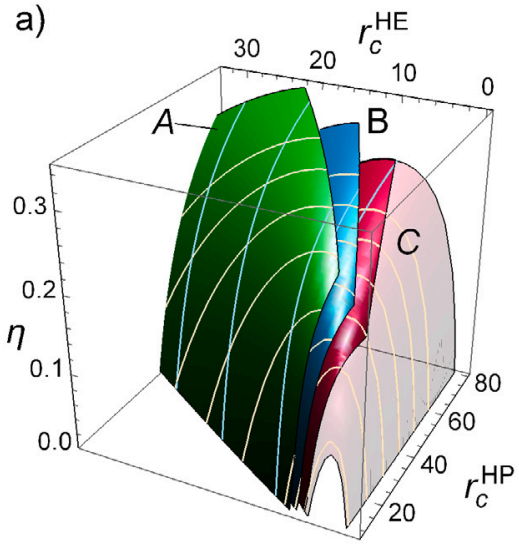

d)

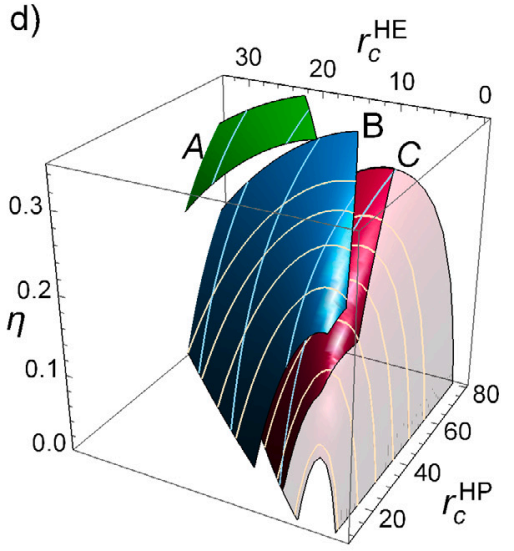

b)

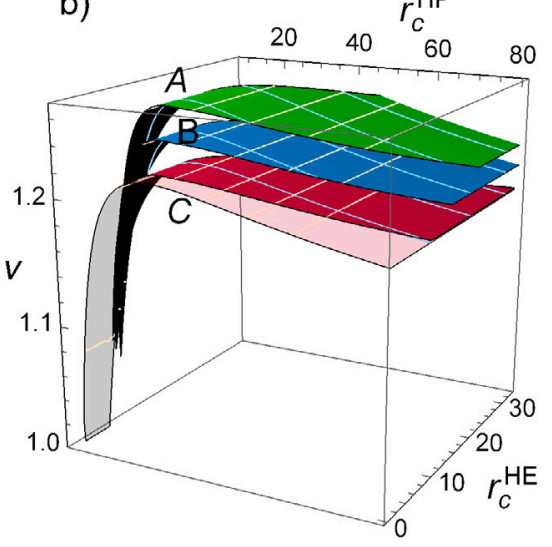

e)



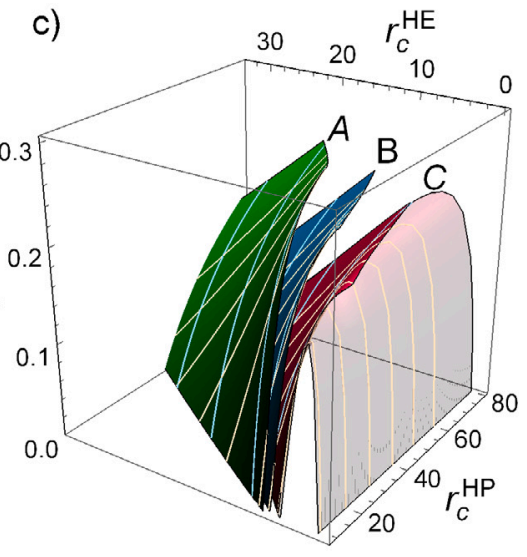

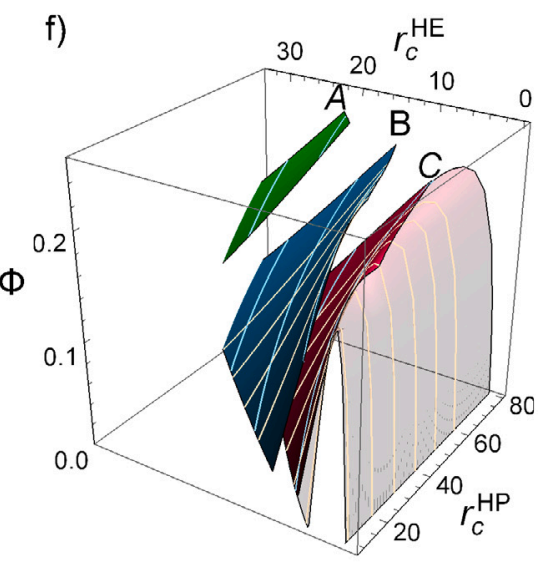

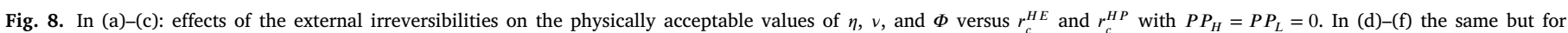

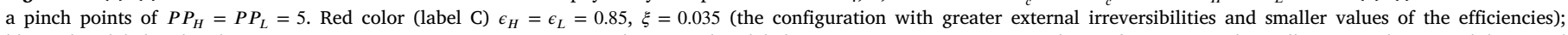

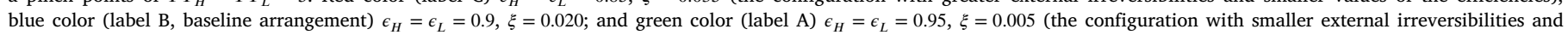
higher values of the efficiencies).

a)

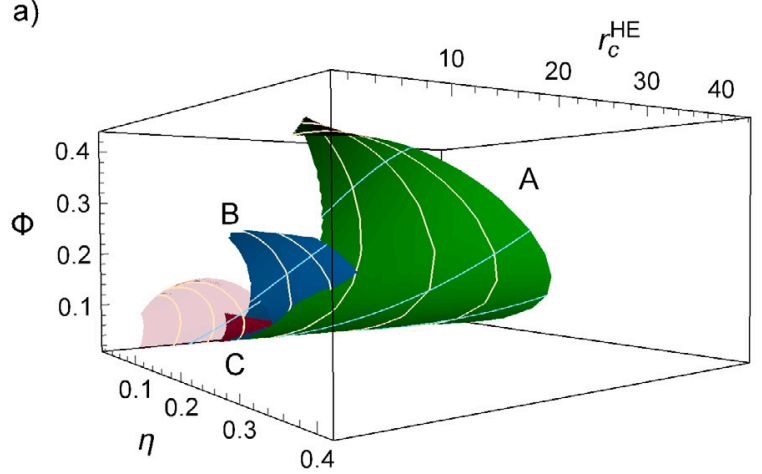

b)

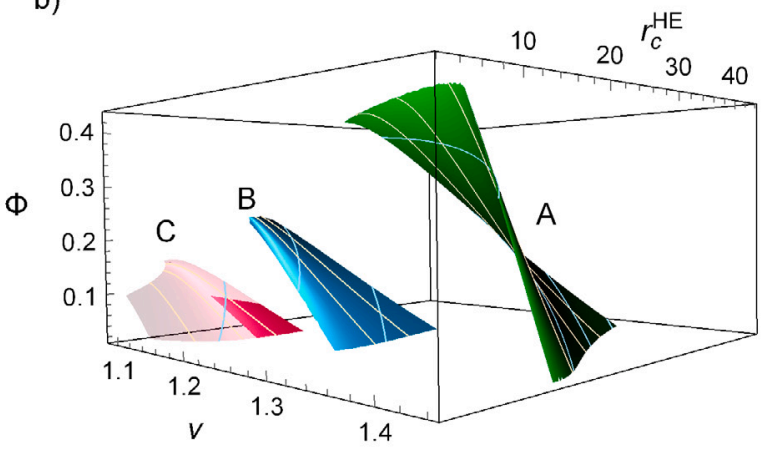

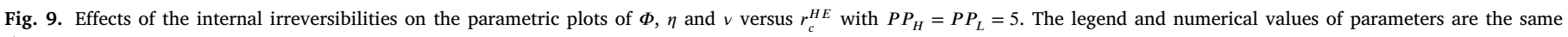
that in Fig. 7.

be stressed the high level of the hot temperature sources but practically the same range of the entropy values.

Finally, it is noted that the physically suitable values of the compression ratios (blue surfaces in above Figs.) are larger for the HP mode $\left(r_{c}^{H P}\right)$ than for the HE mode $\left(r_{c}^{H E}\right)$, according to comments above in Section 4.3. In this way, the outlet temperature of the working fluid in the HP-compressor is enough high to fulfill the PP requirements, especially in the hot side, and the outlet temperature of the working fluid in the HE-compressor is low enough to allow an efficient discharge process.

\section{Discussion and conclusions}

Some comments on the accuracy of the obtained results are in order here. As shown on Figs. 6-10, the predicted values of $\Phi$ are strongly dependent on the parameters accounting for irreversibilities and, indeed, on the compression ratios. Roughly speaking, the predicted values of $\Phi$ are in the range $20-40 \%$ depending on the irreversibilities of the different elected configurations. In the considered particular cases, values of $\Phi$ are in the range between 34-39\%, see Figs. 11-13 and Tables 3-5. It is not easy to make a comparison with other reported values due to the many different theoretical approaches, different cycles, different working fluids, and different media storage used in each case. 
a)



b)

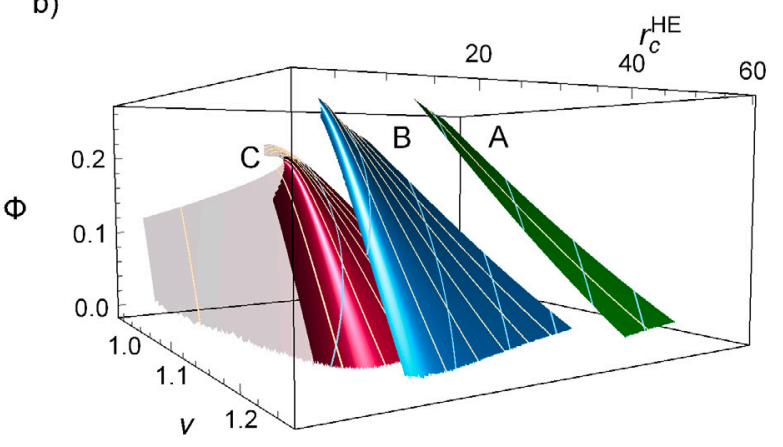

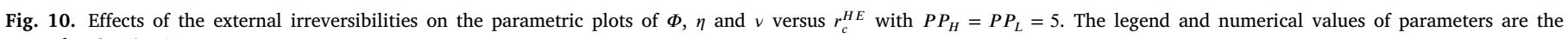
same that in Fig. 8.

a)

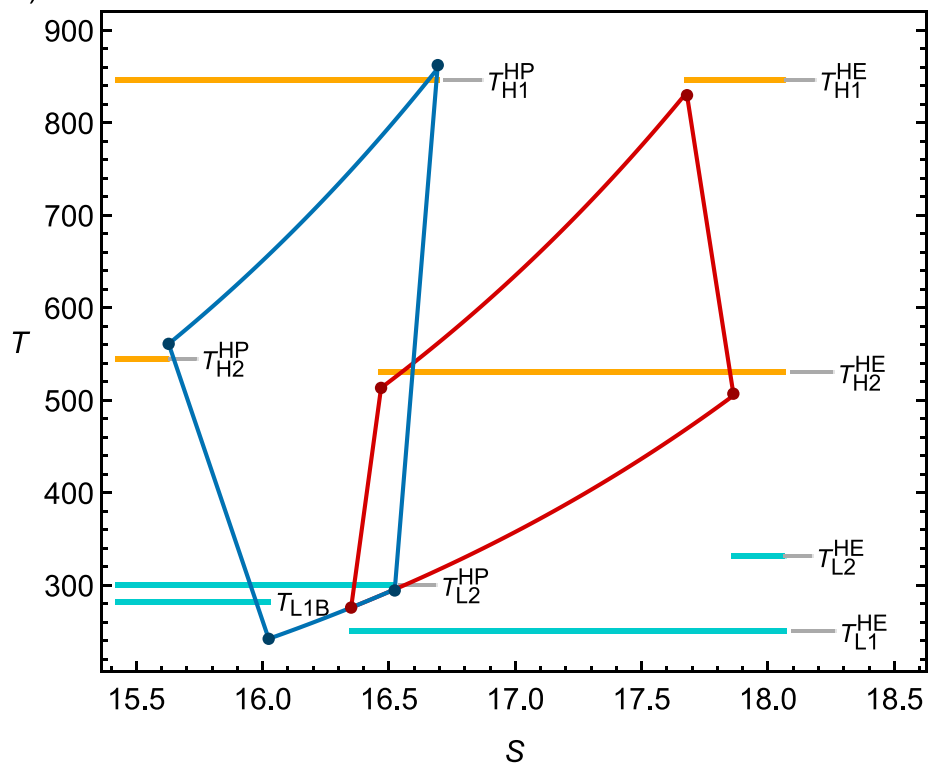

b)

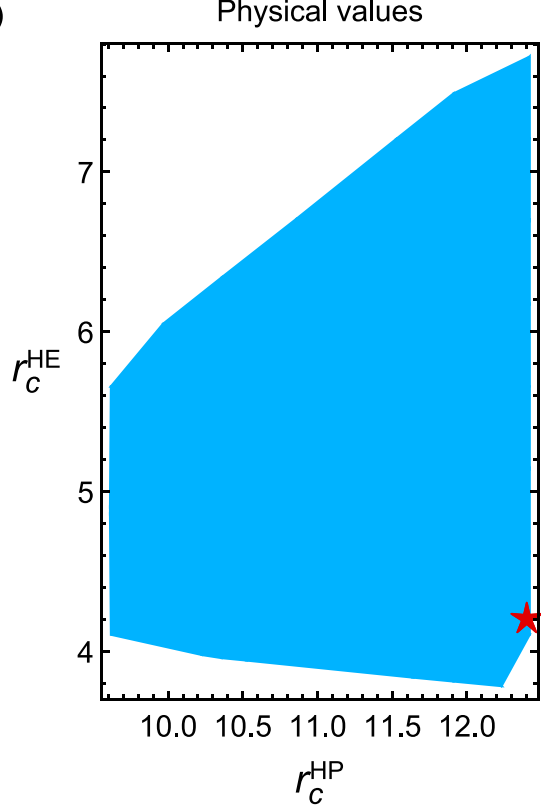

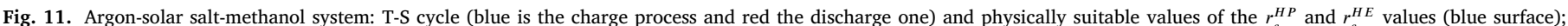

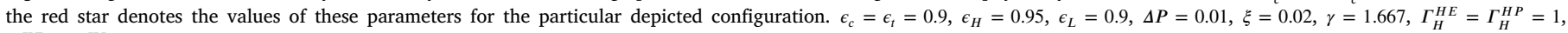


$351 \mathrm{~K}$ and $T_{L, \min }=175 \mathrm{~K}$ for the maximum and minimum values of the liquid methanol temperature; and initial value of the $T_{H 2}^{H P}=550 \mathrm{~K}, r_{c}^{H P}=12.4$ and $r_{c}^{H E}=4.2$.

Table 3

Particular configuration argon-solar salt-methanol: temperatures of the hot side $\left(T_{H 1}\right.$, $T_{H 2}$ ) and cold side $\left(T_{L 1}, T_{L 2}\right)$ for the charge (HP) and discharge (HE) modes. $T_{1}, T_{2}$, $T_{3}$, and $T_{4}$ denote the temperatures of the working fluid in the extreme states of the corresponding cycles. $\eta . v$, and $\Phi$ are the values of the efficiency, COP, and round trip efficiency, respectively. All values correspond to plot in Fig. 11.

\begin{tabular}{llllll}
\hline$T_{H 1}^{H P}$ & $857.5 \mathrm{~K}$ & $T_{H 1}^{H E}$ & $846.3 \mathrm{~K}$ & $\Phi$ & 0.34 \\
$T_{H 2}^{H P}$ & $545 \mathrm{~K}$ & $T_{H 2}^{H E}$ & $529.9 \mathrm{~K}$ & $\eta$ & 0.27 \\
$T_{L 2}^{H P}$ & $300 \mathrm{~K}$ & $T_{L 2}^{H E}$ & $330.9 \mathrm{~K}$ & $v$ & 1.21 \\
$T_{L 1}^{H P}$ & $281.7 \mathrm{~K}$ & $T_{L 1}^{H E}$ & $250 \mathrm{~K}$ & & \\
$T_{1}^{H P}$ & $560.8 \mathrm{~K}$ & $T_{1}^{H E}$ & $513.2 \mathrm{~K}$ & & \\
$T_{2}^{H P}$ & $862.2 \mathrm{~K}$ & $T_{2}^{H E}$ & $829.7 \mathrm{~K}$ & & \\
$T_{3}^{H P}$ & $294.2 \mathrm{~K}$ & $T_{3}^{H E}$ & $506.9 \mathrm{~K}$ & & \\
$T_{4}^{H P}$ & $241.9 \mathrm{~K}$ & $T_{4}^{H E}$ & $275.7 \mathrm{~K}$ & & \\
\hline
\end{tabular}

Values reported by Fernandez et al. [11] for transcritical carbon dioxide cycles with and without integration of solar energy amounts to $52 \%$ and $60 \%$, respectively. Nevertheless, these values could be increased with improved layouts as the one proposed by Morandin et al. [18]. Around the same values are those reported $(55-60 \%)$ by Farres et al. [19]. Closer to the theoretical predictions in this paper are those given by
Table 4

As in previous table but for the air-solar salt-methanol. All values correspond to plot in Fig. 12.

\begin{tabular}{llllll}
\hline$T_{H 1}^{H P}$ & $857.7 \mathrm{~K}$ & $T_{H 1}^{H E}$ & $846.5 \mathrm{~K}$ & $\Phi$ & 0.35 \\
$T_{H 2}^{H P}$ & $545 \mathrm{~K}$ & $T_{H 2}^{H E}$ & $521.8 \mathrm{~K}$ & $\eta$ & 0.27 \\
$T_{L 2}^{H P}$ & $300 \mathrm{~K}$ & $T_{L 2}^{H E}$ & $333 \mathrm{~K}$ & $v$ & 1.21 \\
$T_{L 1}^{H P}$ & $281.5 \mathrm{~K}$ & $T_{L 1}^{H E}$ & $250 \mathrm{~K}$ & & \\
$T_{1}^{H P}$ & $560.8 \mathrm{~K}$ & $T_{1}^{H E}$ & $504.7 \mathrm{~K}$ & & \\
$T_{2}^{H P}$ & $862.4 \mathrm{~K}$ & $T_{2}^{H E}$ & $829.5 \mathrm{~K}$ & & \\
$T_{3}^{H P}$ & $294.1 \mathrm{~K}$ & $T_{3}^{H E}$ & $513.6 \mathrm{~K}$ & & \\
$T_{4}^{H P}$ & $241.5 \mathrm{~K}$ & $T_{4}^{H E}$ & $276.4 \mathrm{~K}$ & & \\
\hline
\end{tabular}

Benato and Stopatto [5] for a similar cycle but including an additional electric heater to increase the HP-compression ratio and using different packed bed materials. For example, these authors reported values of $\Phi$ around $27 \%$ for maximum cycle temperatures of $1000 \mathrm{~K}$, using air as working fluid. Smaller differences for the nine storage materials considered were found. Also, the theoretical predictions by Guo et al. [34] are in agreement with those obtained in this paper. In the same range of values are those reported by Dietrich [17] in an analysis based on Joule cycles for packed bed materials and for heat engine maximum 
a)

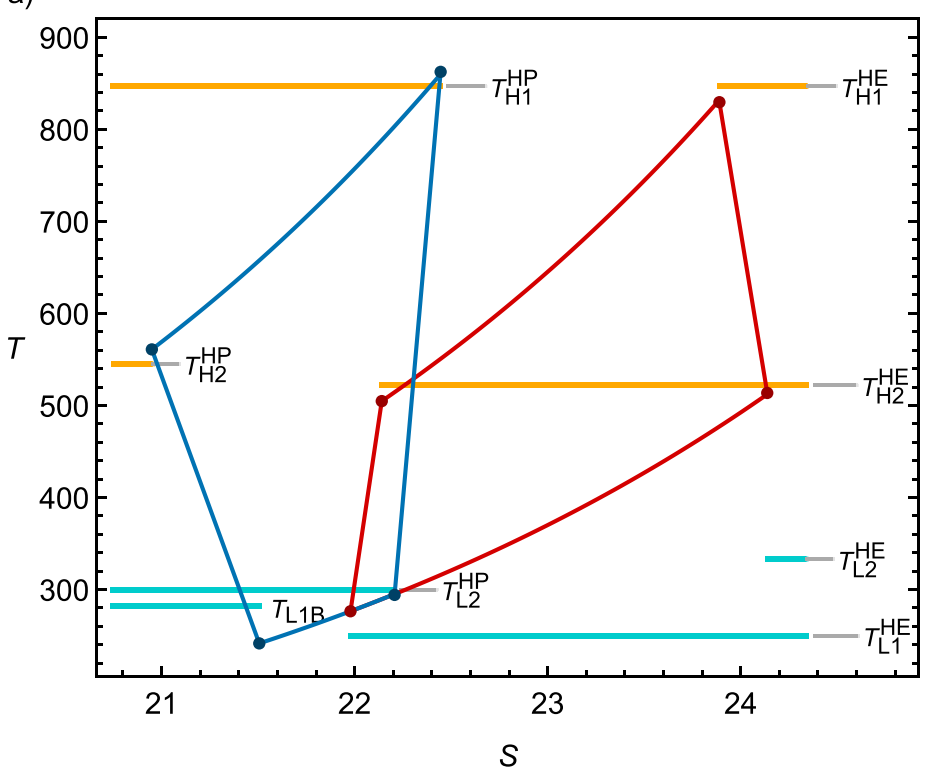

b)

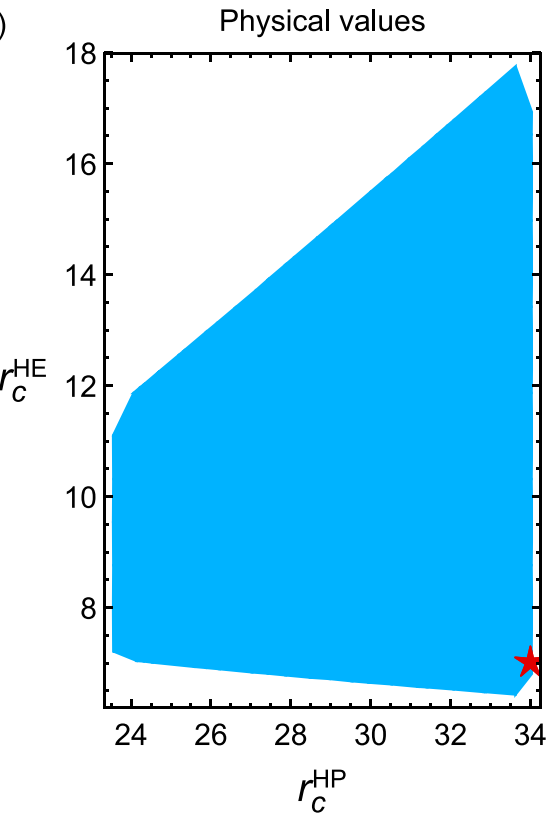



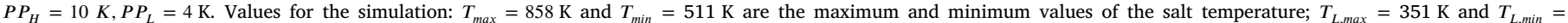
$175 \mathrm{~K}$ for the maximum and minimum values of the liquid methanol temperature; and initial value of the $T_{H 2}^{H P}=550 \mathrm{~K}, r_{c}^{H P}=34$ and $r_{c}^{H E}=7$.

a)

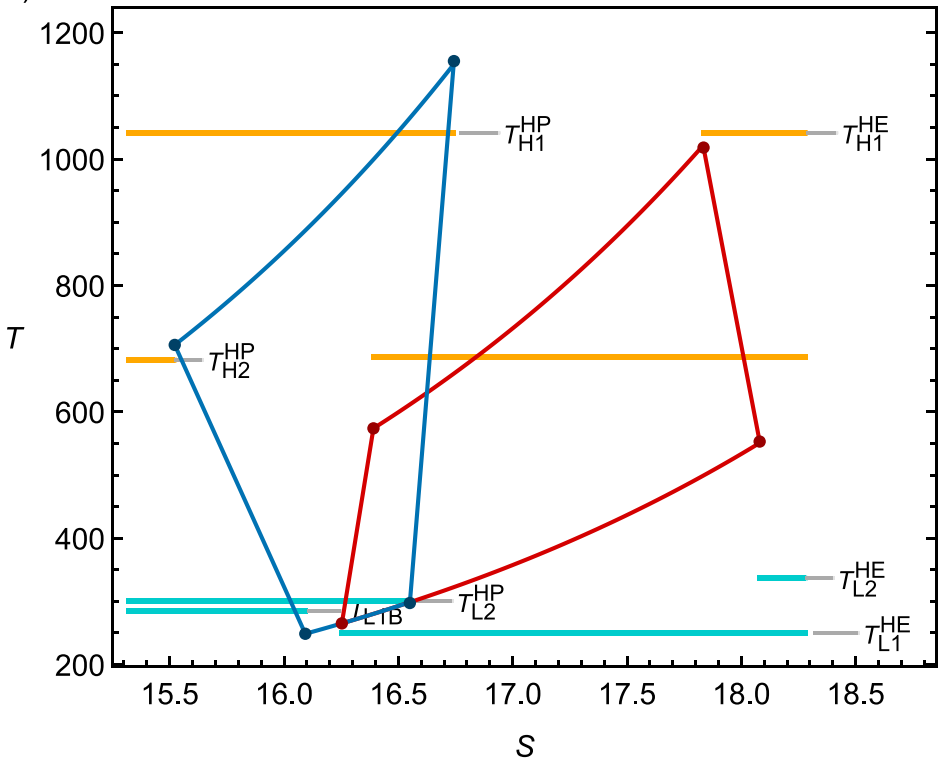

b)

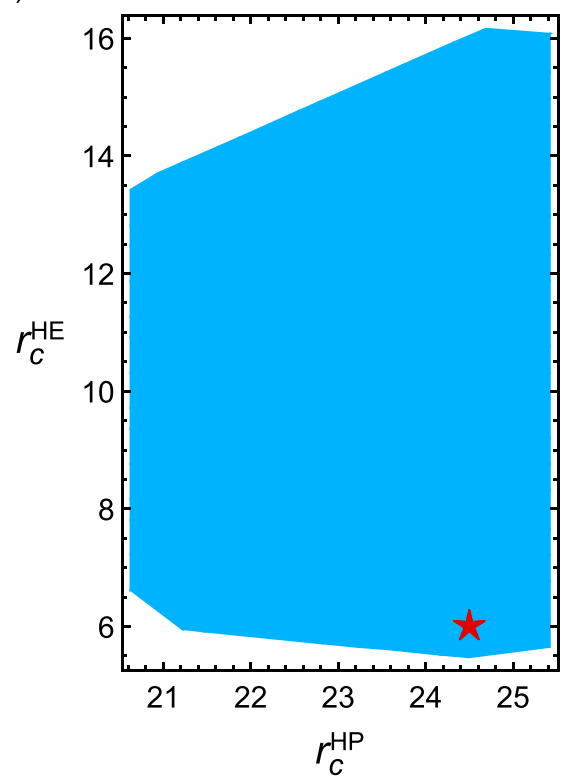



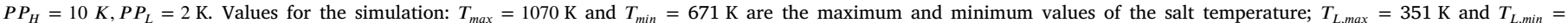
$175 \mathrm{~K}$ for the maximum and minimum values of the liquid methanol temperature; and initial value of the $T_{H 2}^{H P}=690 \mathrm{~K}, r_{c}^{H P}=24.5$ and $r_{c}^{H E}=6$.

pressure between 2 and 4 bar. However, this author note the great influence on the efficiency values of the inlet and outlet temperatures of the working fluid in the thermal storage media and the pressure drops in the working fluid.

Another key factor regarding the obtained theoretical values is the assumption made on the thermal properties of solar salts and cryogenic liquids. These properties have been considered as constant for all involved temperature ranges in between $T_{\min }$ and $T_{\max }$, as compiled in Tables 1 and 2. Indeed, this a crude assumption in order to keep the steady state thermodynamic model as easy as possible with a reduced set of parameters in order to get an entirely analytical simulation scheme, where it is easy to check the influence of the most important plant design parameters. Then, these values can be considered as average between $T_{\min }$ and $T_{\max }$. Obviously, the temperature dependence both of the storage material and of the working fluid should be taken into account, either by appropriate polynomial fits or by using standard reference databases, specially in models focused on storage materials, which is not the case here considered. Calculations reported for air as working fluid with temperature dependent heat capacities in a similar Brayton cycle, gave differences of about $4 \%$ in regards with the assumption of diatomic ideal gas with constant heat capacities [43]. The temperature dependence of the density and heat capacity of the 
Table 5

As in previous table but for the argon-carbonate salt-methanol. All values correspond to plot in Fig. 13.

\begin{tabular}{llllll}
\hline$T_{H 1}^{H P}$ & $1056.7 \mathrm{~K}$ & $T_{H 1}^{H E}$ & $1041.5 \mathrm{~K}$ & $\Phi$ & 0.39 \\
$T_{H 2}^{H P}$ & $682.2 \mathrm{~K}$ & $T_{H 2}^{H E}$ & $682.2 \mathrm{~K}$ & $\eta$ & 0.35 \\
$T_{L 2}^{H P}$ & $300 \mathrm{~K}$ & $T_{L 2}^{H E}$ & $336.3 \mathrm{~K}$ & $\nu$ & 1.12 \\
$T_{L 1}^{H P}$ & $285.4 \mathrm{~K}$ & $T_{L 1}^{H E}$ & $250 \mathrm{~K}$ & & \\
$T_{1}^{H P}$ & $705.8 \mathrm{~K}$ & $T_{1}^{H E}$ & $573.8 \mathrm{~K}$ & & \\
$T_{2}^{H P}$ & $1155 \mathrm{~K}$ & $T_{2}^{H E}$ & $1018.1 \mathrm{~K}$ & & \\
$T_{3}^{H P}$ & $297.4 \mathrm{~K}$ & $T_{3}^{H E}$ & $552.9 \mathrm{~K}$ & & \\
$T_{4}^{H P}$ & $248.7 \mathrm{~K}$ & $T_{4}^{H E}$ & $265.1 \mathrm{~K}$ & & \\
\hline
\end{tabular}

liquid materials has not been tested explicitly in this paper. However, it can be inferred that the generic behaviors plotted in all above figures should remain unchanged but concrete numerical values of the calculated magnitudes could change according to the particular molten salt and cryogenic liquid in each case. Two illustrative examples are given by Laughlin in [7], where the temperature dependence of the main thermal properties of the solar salt (including density and heat capacity) are plotted in the interval $500-800 \mathrm{~K}$ and those of the nhexane in all the liquid range (around of $175-340 \mathrm{~K}$ ). In both cases it can be checked that the variations of $C_{p}$ and $\rho$ are not very relevant, specially for solar salts. The same constancy for the specific heat of methanol at gas-liquid equilibrium pressure can be checked in [44]. Perhaps, the influence of the temperature of the thermal properties may be more important on the engineering design of the heat exchangers (in order to properly account for the pinch point effects) and when liquid TES media with unbalanced mass flow rates are considered [45].

The present study could be improved along different lines: (a) a detailed analysis on the influence of the values of the isentropic efficiencies with different values for the HP and HE cycles. This could introduce subtle behaviors on the charge and discharge modes due to the evident nonlinearity of the coupling; b) the thermodynamic model provides physical insights for design and main losses but a fully optimization method remains as a complex task where trade-off figures of merit should be tackled by multi-objective and multi-parametric methods in order to obtain the possible Pareto front and the associated space of parameters [46]; (c) a third point is the convenience of closed cycles where it may be easier to balance the flow rate of liquid media and the working fluid, avoiding extra losses in the thermal exchanges processes; (d) an additional point concerns the possibility of a regenerator (or recuperator). In such a case the coupling of the regenerator and the heat exchangers [47] should be specially fitted in order to keep the storage liquid temperatures but the expected performance improvements must be faced with a techno-economic analysis [48].

Further improvements should include the specification of time duration of the charge and discharge processes according to grid demands, i.e., a fully dynamical analysis. In this case thermal losses in the surroundings provoke he depletion of stored energy with time. Thus, heat leak should be evaluated as time-dependent processes along the charge, discharge and stabilization phase. Also the heat transfer processes between the working fluid and liquid media requires finite temperature difference, whose associated losses are linked to the time of the operation mode of the storage liquid. As noted by White et al. [14], and at least in packed-bed materials, losses of this kind can vary drastically from a fully discharge/charge process with high temperature gradients to a periodic cycling of the reservoirs with smaller temperature differences but at the expense of reduced storage capacity.

For completeness, costs for the molten salts and of the cryogenic liquids are specified, respectively, in Tables 1 and 2. Comparison with others storage technologies is presented, for instance, in [7]. The consequent thermo-economic to compute the plant costs and profitability is out of the scope of the present steady-state thermodynamic model.

\section{CRediT authorship contribution statement}

D. Salomone-González: Conceptualization, Software, Investigation, Writing review \& editing. J. González-Ayala: Software, Investigation, Writing review \& editing. A. Medina: Investigation, Writing review \& editing. J.M.M. Roco: Conceptualization, Investigation, Writing review \& editing. P.L. Curto-Risso: Conceptualization, Software, Investigation, Writing review \& editing. A. Calvo Hernández: Conceptualization, Investigation, Writing review \& editing.

\section{Declaration of competing interest}

The authors declare that they have no known competing financial interests or personal relationships that could have appeared to influence the work reported in this paper.

\section{Acknowledgments}

Authors acknowledge financial support from Agencia Nacional de Investigación e Innovación (ANII); Fondo Sectorial de Energía, Uruguay; contract FSE-1-2018-1-153077. Valuable comments from two Referees are also acknowledged.

\section{References}

[1] Gallo AB, Simoes-Moreira JR, Costa HK, Santos MM, Moutinho dos Santos E. Energy storage in the energy transition context: A technology review. Renew Sustain Energy Rev 2016;65:800-22.

[2] Luo X, Wang J, Dooner M, Clarke J. Overview of current development in electrical energy storage technologies and the application potential in power system operation. Appl Energy 2015;137:511-36.

[3] Argyrou MC, Christodoulides P, Kalogirou SA. Energy storage for electricity generation and related processes: Technologies appraisal and grid scale applications. Renew Sustain Energy Rev 2018;94:804-21.

[4] Benato A, Stoppato A. Pumped thermal electricity storage: a technology overview. Therm Sci Eng Progr 2018;6:301-15.

[5] Benato A, Stoppato A. Heat transfer fluid and material selection for an innovative pumped thermal electricity storage system. Energy 2018;147:155-68.

[6] Huggins RA. Energy storage fundamentals, materials and applications. second ed.. Springer; 2016.

[7] Laughlin RB. Pumped thermal grid storage with heat exchange. J Renew Sustain Energy 2017;9:1-16.

[8] Wan L, Lin X, Chai L, Peng L, Yu D, Chen H. Cyclic transient behavior of the joule-brayton based pumped heat electricity storage: Modeling and analysis. Renew Sustain Energy Rev 2019;111:523-34.

[9] Morandin M, Maréchal F, Mercangöt M, Buchter F. Conceptual design of a thermo-electrical energy storage system based on heat integration of thermodynamic cycle: part a methodology and base case. Energy 2012;45:375-85.

[10] Morandin M, Mercangöz M, Hemrle J, Maréchal F, Favrat D. Thermoeconomic design optimization of a thermo-electric energy storage system based on transcritical co2 cycles. Energy 2013;58:571-87.

[11] Fernandez R, Chacartegui R, Becerra A, Calderon B, Carvalho M. Transcritical carbon dioxide charge-discharge energy storage with integration of solar energy. J Sustain Dev Energy Water Environ Syst 2019;7:444-65.

[12] Desrues T, Ruer J, Marty P, Fourmigué JF. A thermal energy storage process for large scale electric applications. Appl Therm Eng 2010;30:425-32.

[13] White AJ, Parks G, Markides CN. Thermodynamic analysis of pumped thermal electricity storage. Appl Therm Eng 2013;53:291-8.

[14] White A, McTigue J, Markides C. Wave propagation and thermodynamic losses in packed-bed thermal reservoirs for energy storage. Appl Energy 2014;130:648-57.

[15] McTigue JD, White AJ, Markides CN. Parametric studies and optimisation of pumped thermal electricity storage. Appl Energy 2015;137:800-11.

[16] McTigue JD, Markides CN, White AJ. Performance response of packedbed thermal storage to cycle duration perturbations. J Energy Storage 2018;19:37992.

[17] Dietrich Axel. Assessment of pumped heat electricity storage systems through exergoeconomic analyses (Ph.D. Thesis), Technishe Universitat Darmstadt; 2017.

[18] Morandin M, Maréchal F, Mercangöz M, Buchter F. Conceptual design of a thermo-electrical energy storage system based on heat integration of thermodynamic cycles: Part b: Alternative system configurations. Energy 2012;45:386-96.

[19] Farres-Antunez P, McTigue JD, White AJ. A pumped thermal energy storage cycle with capacity for concentrated solar power integration. In: March offshore energy and storage summit (OSES). Brest, France; 2019, http://dx.doi.org/10. 1109/OSES.2019.8867222. 
[20] Francesco Frate G, Ferrari L, Desideri U. Multi-criteria investigation of a pumped thermal electricity storage (PTES) system with thermal integration and sensible heat storage. Energy Convers Manage 2020;208:112530.

[21] Hassan AH, O’Donoghue L, Sánchez-Canales V, Corberán JM, Payá J, Jockenhöfer H. Thermodynamic analysis of high-temperature pumped thermal energy storage systems: Refrigerant selection, performance and limitations. Energy Rep 2020. http://dx.doi.org/10.1016/j.egyr.2020.05.010, (in press).

[22] Zaversky F, García-Barberena J, Sánchez M, Astrain D. Transient molten salt two-tank thermal storage modeling for CSP performance simulations. Sol Energy 2013;93:294-311.

[23] Peger N, Bauer T, Martin C, Eck M, Wörner A. Thermal energy storage: overview and specific insight into nitrate salts for sensible and latent heat storage. J Nanotechnol 2015;6:1487-97.

[24] Turchi CS, Vidal J, Bauer M. Molten salt power towers operating at 600-650: Salt selection and cost benefits. Sol Energy 2018;164:38-46.

[25] Cengel Y. Heat transfer. A practical approach. second ed.. McGraw-Hill Education; 2002, ISBN-10: 9780072458930.

[26] Davenne TR, Garvey SD, Cardenas B, Simpson MC. The cold store for a pumped thermal energy storage system. J Energy Storage 2017;14:295-310.

[27] Tournier JMP, El-Genk MS. Properties of noble gases and binary mixtures for closed brayton cycle applications. Energy Convers Manage 2008;49:469-92.

[28] Habibi H, Zoghi M, Chitsaz A, Javaherdeh K, Ayazpour M, Bellos E. Working fuid selection for regenerative supercritical brayton cycle combined with bottoming ORC driven by molten salt solar power tower using energy and exergy analysis. Sustain Energy Technol Assess 2020;39:100699.

[29] Wan Z, Wei J, Qaisrani MA, Fang J, Tu N. Evaluation on thermal and mechanical performance of the hot tank in the two-tank molten salt heat storage system. Appl Therm Eng 2020;167:114775.

[30] Thess A. Thermodynamic efficiency of pumped heat electricity storage. Phys Rev Lett 2013;111:110602.

[31] Chen J, Guo J. Comment on thermodynamic efficiency of pumped heat electricity storage. Phys Rev Lett 2016;116:158901.

[32] Guo J, Yang H, Lin B. Performance characteristics and parametric optimization of weak dissipative pumped thermal electricity storage system. Energy Convers Manage 2018;157:527-35.

[33] Guo J, Cai L, Chen J, Zhou Y. Performance optimization and comparison of pumped thermal and pumped cryogenic electricity storage system. Energy 2016;106:260-9.
[34] Guo J, Cai L, Chen J, Zhou Y. Performance evaluation and parametric choice criteria of a brayton pumped thermal electricity storage system. Energy 2016;113:693-701.

[35] https://tradingeconomics.com/commodity/propane.

[36] Roco JMM, Velasco S, Medina A, Hernandez AC. Optimum performance of a regenerative brayton thermal cycle. J Appl Phys 2001;82:2735-41.

[37] White AJ. Thermodynamic analysis of the reversed joule-brayton cycle heat pump for domestic heating. Appl Energy 2009;86:2243-450.

[38] Ahmadi MH, Ahmadi MA, Pourfayaz F, Bidi M. Thermodynamic analysis and optimization for an irreversible heat pump working on reversed brayton cycle. Energy Convers Manage 2016;110:260-7.

[39] Bejan A. Advanced engineering thermodynamics. New York: Wiley; 1988, Chap. 8.

[40] Araujo AK, Medina GI. Analysis of the effects of climatic conditions, loading level and operating temperature on the heat losses of two-tank thermal storage systems in CSP. Sol Energy 2018;176:358-69.

[41] Mahdavi N, Khalilarya S. A novel method for assessment of pinch point characteristics of heat exchangers with different combinations of pure fluid and binary mixture as hot and cold streams. Energy Convers Manage 2019;181:342-58.

[42] Sánchez-Orgaz S, Medina A, Calvo Hernández A. Thermodynamic model and optimization of a multi-step irreversible brayton cycle. Energy Convers Manage 2010;51:2134-43.

[43] Merchán RP, Santos MJ, Medina A, Calvo Hernández A. Thermodynamic model of a hybrid brayton thermosolar plant. Renew Energy 2018;128:473-83.

[44] https://www.engineeringtoolbox.com/methanol.

[45] Wan L, Lin X, Chai L, Peng L, Yu D, Liu J, Chen H. Unbalanced mass flow rate of packed bet thermal energy storage and its influence on the joule-brayton based pumped thermal electricity storage. Energy Convers Manage 2019;185:593-602.

[46] Sánchez-Orgaz S, Pedemonte M, Ezzatti P, Curto-Risso PL, Calvo Hernández A. Multi-objective optimization of a multi-step solar-driven brayton plant. Energy Convers Manage 2015;99:346-58.

[47] Sánchez-Orgaz S, Medina A, Calvo Hernández A. Recuperative solar-driven multi-step gas turbine power plants. Energy Convers Manage 2013;67:171-8.

[48] Mahdi Naserian M, Farahat S, Sarhaddi F. Exergoeconomic multi objective optimization and sensitivity analysis of a regenerative brayton cycle. Energy Convers Manage 2016;117:95-105. 